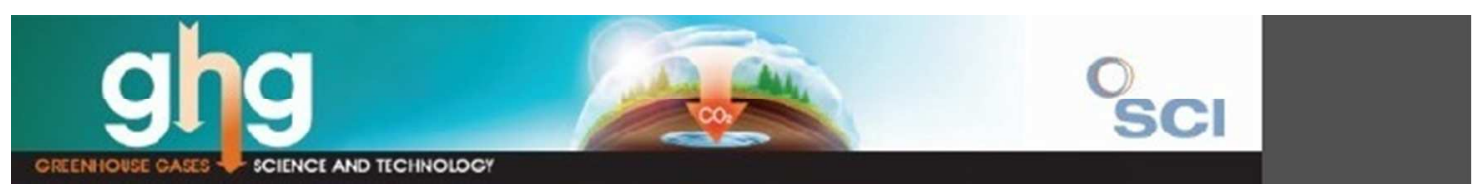

\title{
Accelerated carbonation by Cement Kiln Dust in aqueous slurries: chemical and mineralogical investigation
}

\begin{tabular}{|r|l|}
\hline Journal: & Greenhouse Gases: Science and Technology \\
\hline Manuscript ID & GHG-16-0126.R2 \\
\hline Wiley - Manuscript type: & Original Research Article \\
\hline Complete List of Authors: & $\begin{array}{l}\text { Medas, Daniela; Universita degli Studi di Cagliari, Department of Chemical } \\
\text { and Geological Sciences } \\
\text { Cappai, Giovanna; Universita degli Studi di Cagliari, DICAAR, Department } \\
\text { of Civil and Environmental Engineering and Architecture } \\
\text { De Giudici, Giovanni; Universita degli Studi di Cagliari, Department of } \\
\text { Chemical and Geological Sciences } \\
\text { Piredda, Martina; Universita degli Studi di Cagliari, DICAAR, Department of } \\
\text { Civil and Environmental Engineering and Architecture } \\
\text { Podda, Simona; Center for Advanced Studies Research and Development, } \\
\text { Parco Scientifico Polaris }\end{array}$ \\
\hline Keywords: & $\begin{array}{l}\text { Accelerated carbonation, Ca-(Al)-silicate, Ca carbonate, CO<sub }>2</ s u b>~ \\
\text { sequestration, Cement Kiln Dust }\end{array}$ \\
\hline
\end{tabular}




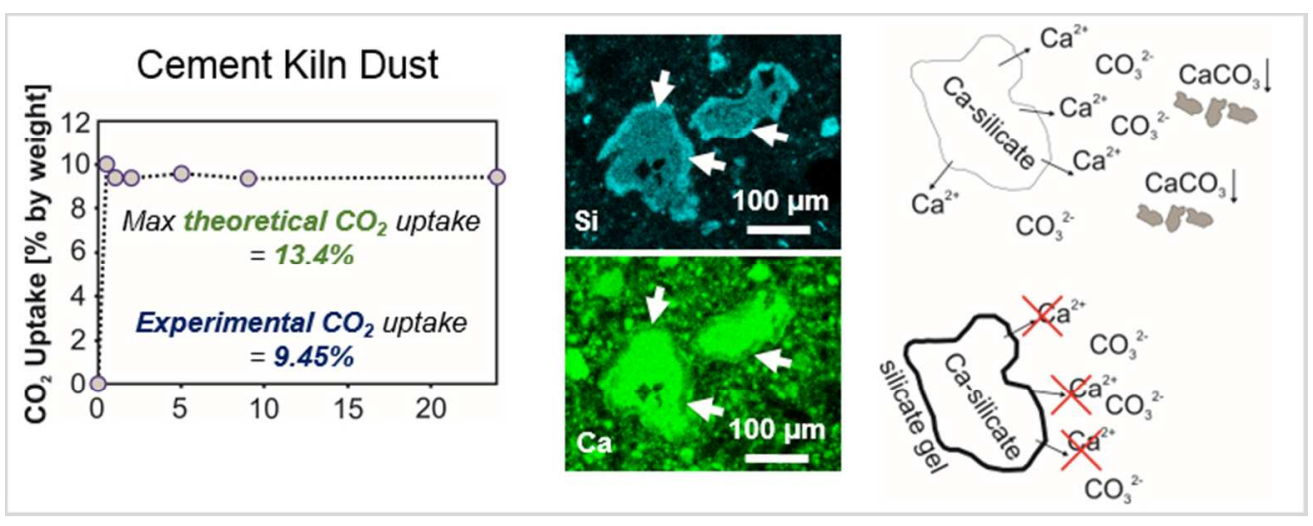

Graphical Abstract

$203 \times 78 \mathrm{~mm}(96 \times 96 \mathrm{DPI})$ 
1 Accelerated carbonation by Cement Kiln Dust in aqueous slurries:

\section{2 chemical and mineralogical investigation}

3 Daniela Medas $^{\mathrm{a},{ }^{*} \text {, Giovanna Cappai }}{ }^{\mathrm{b}}$, Giovanni De Giudici ${ }^{\mathrm{a}}$, Martina Piredda $^{\mathrm{b}}$, Simona Podda ${ }^{\mathrm{c}}$

$4{ }^{a}$ Department of Chemical and Geological Sciences, University of Cagliari, via Trentino 51, 09127, 5 Cagliari, Italy

$6{ }^{\mathrm{b}}$ DICAAR, Department of Civil and Environmental Engineering and Architecture, University of 7 Cagliari, Piazza d'Armi 1, 09123, Cagliari, Italy

$8 \quad{ }^{\mathrm{c}}$ CRS4 - Center for Advanced Studies, Research and Development in Sardinia, Parco Scientifico $9 \quad$ Polaris, Pula 09010, Italy.

11 *phone +39070 6757721 - fax +39 070 282236; e-mail: dmedas@unica.it

\section{Abstract}

14 Cement Kiln Dust accelerated carbonation in aqueous slurries at $25^{\circ} \mathrm{C}$ and 3 bar $\mathrm{PCO}_{2}$ was

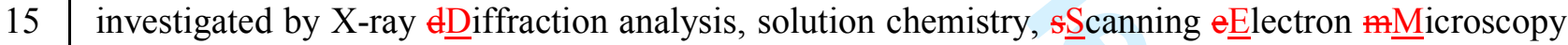
and eEnergy 4 Dispersive s.Spectroscopy to better understand chemical and mineralogical processes governing $\mathrm{CO}_{2}$ uptake. Dissolution of lime, portlandite and ettringite occurs primarily in the 18 carbonation process. These provide $\mathrm{Ca}^{2+}$ ions to react with $\mathrm{CO}_{3}{ }^{2-}$ ions leading to calcite bulk 19 precipitation from solution. Concomitantly, the dissolution of $\mathrm{Ca}-(\mathrm{Al})$-silicate grains takes place but 20 it is limited by the formation of a Si-rich and Ca-depleted rim which appears onto the grain surfaces 21 due to an initial hydration step. The Si-rich decalcified rim hinders the diffusion of $\mathrm{Ca}^{2+}$ ions from 22 the core of silicate grains to the bulk solution. The diffusion of $\mathrm{Ca}$ ions through the rim is then the 23 rate limiting step for the carbonation of $\mathrm{Ca}-(\mathrm{Al})$-silicate, that accounts for up to $4 \%$ of the 24 carbonation potential. Achieved results elucidate the processes governing $\mathrm{CO}_{2}$ uptake by $\underline{\text { Cement }}$ 
25 Kiln Dusteement kiln dust, and are fundamental in the perspective of enhanced $\mathrm{CO}_{2}$ sequestration by $\underline{\text { Cement Kiln Dusteement kiln dust. }}$

\section{Keywords}

28 Accelerated carbonation, Cement Kiln Dusteement kiln dust, $\mathrm{Ca}-(\mathrm{Al})$-silicate, $\mathrm{Ca}$ carbonate, $\mathrm{CO}_{2}$ 29 sequestration

\section{1. Introduction}

31 Carbon dioxide $\left(\mathrm{CO}_{2}\right)$ is the most important greenhouse gas resulting from the human activity, and

32 it is responsible for about two-thirds of the enhanced greenhouse effect. ${ }^{1}$ The development of

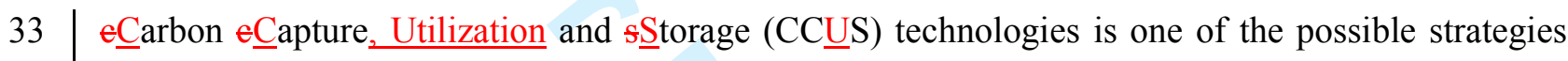
34 for reducing $\mathrm{CO}_{2}$ in the atmosphere. Among the CCL $\mathrm{US}$ technologies, $\mathrm{CO}_{2}$ utilization by 35 mineralization as carbonates is often referred as accelerated carbonation technology. ${ }^{2,3}$ Mineral 36 carbonation is a process whereby $\mathrm{CO}_{2}$ is chemically reacted with $\mathrm{Ca}$ and/or $\mathrm{Mg}$ containing minerals 37 to form stable carbonate materials. Carbonation can occur naturally during the weathering process 38 of minerals, ${ }^{2}$ consisting in the reaction between natural alkaline silicates and atmospheric $\mathrm{CO}_{2}$. This 39 process removes $\mathrm{CO}_{2}$ from the atmosphere by neutralizing the acid gas with mineral alkalinity. ${ }^{4}$

40 Weathering of $\mathrm{Ca}$ and $\mathrm{Mg}$ (hydr)oxides and silicates is a major consumer of excess atmospheric $41 \mathrm{CO}_{2}$ on a geological timescale. ${ }^{5}$ However, the kinetics of carbonation is very slow at ambient 42 condition due to the relatively low $\mathrm{CO}_{2}$ concentration, about $0.03-0.06 \%$ by volume. ${ }^{4,6,7}$ Accelerated 43 carbonation involves alkaline materials reacting with $\mathrm{CO}_{2}$ in controlled conditions, aiming to reduce 44 the time required for complete carbonation and to accelerate the reaction to a timescale of a few 45 minutes or hours, ${ }^{2,3,8}$ with the potential to capture billions of tonnes of carbon per year. ${ }^{9}$

46 Several up-to-date reviews on the state of the art of mMineral $€$ Carbonation $(\mathrm{MC})$ technologies are 47 available, reporting an increasing number of research projects worldwide and thus highlighting the 48 interest and the potentiality of mineral carbonation within CC $\underline{\text { US technologies. }}{ }^{10-12}$ The undeniable 49 benefit of mineral carbon sequestration is being the most permanent and safe method of carbon 
50 storage. However, despite the well documented advantages, the technology is not mature yet. After

5120 years of R\&D studies since its first proposal as CCU $\underline{\text { S }}$ method, ${ }^{3}$ the state of development is still 52 at the laboratory demonstration scale and only some MC technologies have recently approached the 53 commercial scale. ${ }^{10,12}$ The main reasons for limited application on a larger scale are the low reaction 54 conversion, the slow kinetics and the energy intensity of the accelerated carbonation processes, 55 which affect the economic viability of the technology. ${ }^{10,12}$ It is well recognized that to reach the 56 highest carbonation efficiency, the major challenges are represented by the identification of the 57 controlling mechanisms and optimal operating parameters. In particular, when carbonation of 58 alkaline materials is performed through aqueous route, the following three mechanisms could be 59 involved: 1) dissolution of $\mathrm{Ca}$ and $\mathrm{Mg}$ reactive species from the solid matrix; (2) dissolution of $\mathrm{CO}_{2}$ 60 into the liquid phase and conversion of carbonic acid to bicarbonate/carbonate ions; (3) consequent 61 nucleation and precipitation of carbonates. ${ }^{2,13}$ The material particle size, the temperature, the gas 62 pressure, the liquid/solid $(\mathrm{L} / \mathrm{S})$ ratio are important parameters that could differently affect the 63 carbonation mechanisms, ${ }^{2,10}$ and a prediction on a theoretical basis of the main effects and of the 64 joint interactions between the different factors is hard to be derived. At present, the possibility to 65 enhance the reaction kinetics and the extent of the carbonation process, as well as to improve its 66 economic viability, are the focus of several accelerated carbonation experiments being conducted 67 worldwide. $^{14,15}$

68 Some of the above-mentioned drawbacks could be avoided when alkaline wastes are used as 69 feedstock instead of mineral resources. In fact, alkaline residues generally contain highly reactive $70 \mathrm{Ca}$ and $\mathrm{Mg}$ species, potentially suitable for achieving high and fast carbonate conversions without 71 the need of pre-treatment or energy intensive operating conditions. Moreover, they are available at 72 low cost near $\mathrm{CO}_{2}$ point source emissions and allow avoiding the exploitation of natural resources. 73 Finally, the resulting $\mathrm{pH}$ neutralization and mineral modification induced by carbonation could 74 improve the chemico-physical characteristics of the waste material, allowing for a safer disposal or 75 for a beneficial re-use. ${ }^{11,16,17}$ 
Among alkaline industrial residues that can be used as a source of carbonate-forming ions, $\underline{\text { Cement }}$ Kiln Dusteement kiln dust (CKD), a by-product from cement industry, appears interesting due to its suitable composition and its availability near $\mathrm{CO}_{2}$ point source emission. The cement industry generates in fact around $5 \%$ of global $\mathrm{CO}_{2}$ emissions $^{17}$ and produces yearly 30 millions of tonnes of

1 the cement plant $\mathrm{CO}_{2}$ emissions. $\mathrm{CKD}$ is a potential hazardous waste, in part because of the caustic nature and its potential to be a skin, eye, and respiratory irritant. In addition, contaminants from the raw materials and fuels tend to concentrate in CKD. ${ }^{19,20}$ Previous works on $\mathrm{CKD}^{21-23}$ mainly focused on the improvement of the carbonation process by varying operating conditions such as $\mathrm{CO}_{2}$ pressure, temperature, liquid-to-solid $(\mathrm{L} / \mathrm{S})$ ratio, $\mathrm{CO}_{2}$ humidity, $\mathrm{CO}_{2}$ flow rate, liquid flow rate, particle size, and solid pre-treatment. Gunning et al. ${ }^{16}$ studied the effects of the carbonation of the CKD on the chemistry, microstructure and leaching characteristics of the solid material, whereas Anderson et al. ${ }^{24}$ investigated the influence that the carbonation of CKD, performed at ambient temperature and pressure, has on the mineral composition and calcite precipitation mechanisms. At the current state of knowledge and in view of a scale-up of the process, further 1 laboratory scale studies are needed with the aim to better elucidate the mechanisms that may limit 2 the rate or the extent of the accelerated carbonation process on CKD.

3 In a previous work, our research group carried out accelerated carbonation experiments on CKD 4 focused on the assessment of the optimal operating condition in terms of $\mathrm{CO}_{2}$ sequestration and reaction kinetics. ${ }^{25}$ The operating parameters such as $\mathrm{L} / \mathrm{S}$ ratio, $\mathrm{CO}_{2}$ pressure and temperature were 6 found to differently affect the $\mathrm{CO}_{2}$ uptake. The higher $\mathrm{CO}_{2}$ uptake and reactive species conversion 7 were attained at lower temperatures and under slurry-phase conditions. In particular, the optimal 8 water content and the optimal $\mathrm{CO}_{2}$ pressure were found to be $\mathrm{L} / \mathrm{S}=5 \mathrm{~L} / \mathrm{kg}$ and $\mathrm{PCO}_{2}=3$ bar, 9 respectively, allowing to achieve a The_higher $\mathrm{CO}_{2}$ sequestration-uptake ofeapacity $\left(\_9.80 \%\right.$. 00 However, fwas achieved at a $\mathrm{L} / \mathrm{S}=2.5$ and at operating pressure of 3 bar, but the maximum theoretical $01 \mathrm{CO}_{2}$ sequestration capacity of $13.4 \%$ was not reached. Experimental results indicated that during 
102 carbonation of CKD the reaction rate slows down, with an initial rapid conversion of alkaline

103 species into carbonates and a more gradual conversion of residual un-reacted species, without

104 reaching a complete conversion.

105 In the present study, CKD was carbonated in aqueous suspension (slurry-phase carbonation) at

$10625^{\circ} \mathrm{C}$ and $\mathrm{CO}_{2}$ pressure of 3 bar to elucidate chemical and mineralogical processes limiting the $\mathrm{CO}_{2}$

107 sequestration yield-capacity by combining X-ray dDiffraction analysis (XRD), s $\underline{\text { Scanning eElectron }}$

108 mMicroscopy (SEM), chemical analysis of solution in contact with the alkaline waste during the

109 carbonation experiment, and speciation and equilibrium calculation. Results can be useful to

110 improve understanding of the governing processes, and allow for better utilization of $\mathrm{CKD}$ in $\mathrm{CO}_{2}$

111 sequestration.

\section{2. Materials and methods}

\section{$113 \quad 2.1$ Cement Kiln Dust and carbonation experiment}

114 The CKD analysed in this study was collected from a cement plant in the South Sardinia (Italy).

115 The plant adopts a semidry process based on Lepol Grate Technology in which hot gases, coming

116 from the kiln, from an auxiliary burner and, sometimes, from the recovered hot gas of the cooler,

117 are used in two chambers for drying and pre-calcining the raw materials. A total mass sample of 60

$118 \mathrm{~kg}$ was collected at the air pollution control devices treating the exhaust gases from the kiln system

119 (electrostatic filter) and stored in airtight containers at room temperature.

120 A detailed chemical composition of CKD is reported in Table 1. Calcium is the major component

121 by far $(\mathrm{CaO}, 47 \%)$, while $\mathrm{Mg}(\mathrm{MgO}, 2.6 \%), \mathrm{Na}\left(\mathrm{Na}_{2} \mathrm{O}, 0.28 \%\right)$ and $\mathrm{K}\left(\mathrm{K}_{2} \mathrm{O}, 1.3 \%\right)$ are present in

122 small amounts. This composition is within the typical range reported in literature. ${ }^{16,22,26}$ Among the

123 potential harmful elements, $\mathrm{Pb}(463 \mathrm{mg} / \mathrm{kg}), \mathrm{V}$ (363 mg/kg), Zn (177/mg/kg), Cu (163 mg/kg), Ni

$124(97 \mathrm{mg} / \mathrm{kg}), \mathrm{Mn}(39 \mathrm{mg} / \mathrm{kg}), \mathrm{Tl}(25 \mathrm{mg} / \mathrm{kg}), \mathrm{Cr}(22 \mathrm{mg} / \mathrm{kg})$, and As $(16 \mathrm{mg} / \mathrm{kg})$ are the most 125 abundant. 
126 The operating conditions to be adopted for the accelerated carbonation experiment, in terms of 127 Ttemperature, $\mathrm{CO}_{2}$ pressure and water content, procedure was performedwere selected on the basis 128 of eonsidering the results obtained in a previous study by our research group (Cappai et al. ${ }^{25}$. The 129

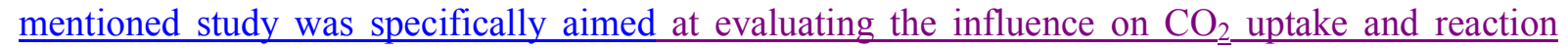
kinetics exerted by the operating parameters such as $\mathrm{L} / \mathrm{S}$ ratio $(0.4 ; 1 ; 3 ; 5 ; 10 \mathrm{~L} / \mathrm{kg}), \mathrm{CO}_{2}$ pressure $131(1 ; 3 ; 5 ; 10$ bar $)$ and temperature $\left(25 ; 50 ; 100{ }^{\circ} \mathrm{C}\right)$. HThe higherst $\mathrm{CO}_{2}$ uptake and reactive species 132 conversion were attained at lower temperatures $\left(25^{\circ} \mathrm{C}\right)$ and under slurry-phase conditions. In 133 particular, the higherst $\mathrm{CO}_{2}$ sequestration capacity $(9.80 \%)$ was achieved at a $\mathrm{L} / \mathrm{S}=5$ and at operating 134 pressure of 3 bar (please see Figure S1 in the Supplementary Material section, reporting the $\mathrm{CO}_{2}$ 135 uptakes over time obtained at $\mathrm{T}=25^{\circ} \mathrm{C}$ and at the different pressures and $\mathrm{L} / \mathrm{S}$ ratio adopted). In the 136 present study, a quantity of $100 \mathrm{~g}$ of dry sample was mixed with $500 \mathrm{~g}$ of deionized water (slurry137 phase process) and exposed to a $100 \% \mathrm{CO}_{2}$ atmosphere, at a pressure of 3 bar and a temperature of $13825^{\circ} \mathrm{C}$. Test was performed in a 21 pressurized reactor equipped with a 1.71 internal Teflon vessel, 139 an electric jacket for temperature control, and a stirred shaft. At each set time $(0.5,1,2,3,5,8$ and 14024 hours), a dedicated sampling device was used for drawing slurry samples, which were filtered 141 over a $1.2 \mu \mathrm{m}$ membrane. Liquid phase was used for chemical analysis (see 2.3 paragraph). Solid 142 samples were oven dried at $40^{\circ} \mathrm{C}$ for 24 hours and stored in closed containers for subsequent 143 analysis. The experiment was performed in triplicate. Obtained results are perfectly in agreement 144 and observed variations are in the range of the experimental errors. For this reason and the sake of 145 clarity, in the result and discussion paragraphs, we prefer to present the mean values of chemical 146 data, and the corresponding standard deviation is indicated by error bars in reported graphics. The 147 specific curves of each experiment are reported in the Supplementary Materials (Fig. S2, S3, S4 and $148 \underline{\mathrm{S} 5})$. 


\section{$149 \quad 2.2$ X-ray diffraction and electron microscopy study}

150 An aliquot of $200 \mathrm{mg}$ of dried powder of untreated CKD, and solid samples collected at each set

151 time during the carbonation experiment were slightly ground in an agate mortar, and subjected to

152 XRD analysis, using conventional $\theta-2 \theta$ equipment (Panalytical) with $\mathrm{Cu} \mathrm{K} \alpha$ wavelength radiation

$153(\lambda=1.54060 \AA)$, operating at $40 \mathrm{kV}$ and $40 \mathrm{~mA}$, using the $\mathrm{X}^{\prime}$ Celerator detector.

154 SEM imaging and EDS (eEnergy 4 Dispersive sp Spectroscopy) analysis (before and after the 155 carbonation) were carried out using a field emission (Schottky thermal field emitter) SEM, under 156 high vacuum conditions. In addition, thin sections for SEM imaging were prepared by incorporating $157 \mathrm{CKD}$ in an epoxy resin and subsequently flattening to an appropriate thickness and polishing in 158 order to highlight the rim of the reaction. In order to obtain better quality images, samples were 159 gold coated before observation, using a SEM Coating Unit PS3 (Agar Aids for Electron 160 Microscopy).

$161 \quad 2.3$ Assessment of $\mathrm{CO}_{2}$ sequestration

162 Total carbon content analysis (LECO CHN-1000 Element Analyzer) were performed in duplicate 163 on dried solid residues obtained at the different durations. Mean values from TC (total carbon) 164 content analysis were used to estimate the $\mathrm{CO}_{2}$ uptake, with an error (difference between mean and 165 real value) always lower than $3 \%$ of the average value. The obtained mean values, expressed as 166 weight $\%$ of $\mathrm{CO}_{2}\left(\mathrm{CO}_{2}\right.$ carbonated [\%]) were used to calculate the $\mathrm{CO}_{2}$ uptake by applying the 167 equation 1, were $\mathrm{CO}_{2 \text { initial }}[\%]$, is the TC content of the untreated $\mathrm{CKD}$, again expressed as weight $\%$ 168 of $\mathrm{CO}_{2}$ (Equation 1).

$$
\mathrm{CO}_{2} \text { uptake }[\%]=\frac{\mathrm{CO}_{2_{\text {carbonated }}}[\%]-\mathrm{CO}_{2 \text { initial }}[\%]}{100-\mathrm{CO}_{2_{\text {carbonated }}}[\%]} * 100 \quad \text { Equation } 1
$$

172 The degree of sequestration in terms of reactive species conversion yields was also evaluated, by 173 comparing the amount of $\mathrm{CO}_{2}$ sequestered in each test to the maximum amount theoretically 
174 possible (Equation 2). The theoretical limit of uptake was calculated based on the Steinour formula

175 (Equation 3), ${ }^{27}$ which assumes the full stoichiometric conversion to carbonates of the reactive 176 | alkaline species-.

177

$178 \eta \eta \%]=\frac{\mathrm{CO}_{2} \text { uptake }[\%]}{\text { ThCO }_{2} \text { uptake }[\%]} * 100 \quad$ Equation 2

$179 \mathrm{ThCO}_{2}$ uptake $\lfloor \%\rfloor=0.785\left(\mathrm{CaO}\lfloor \%\rfloor-0.56 \mathrm{CaCO}_{3}\lfloor \%\rfloor-0.7 \mathrm{SO}_{3}\lfloor \%\rfloor\right)+1.091 \mathrm{MgO}\lfloor \%\rfloor+$

$180 \quad 0.71 \mathrm{Na}_{2} \mathrm{O}[\%\rfloor+0.468\left(\mathrm{~K}_{2} \mathrm{O}\lfloor \%\rfloor-0.632 \mathrm{KCl}\lfloor \%\rfloor\right) \quad$ Equation 3

\section{$182 \quad 2.4$ Chemical analysis of solutions}

183 The liquid phase was further filtered using a $0.45 \mu \mathrm{m}$ Millipore filtering system and $\mathrm{pH}$, redox 184 potential, conductivity, alkalinity, trace elements and anions were evaluated on filtered aliquots. $\mathrm{pH}$ 185 values were measured by a Ross electrode connected to a pH-meter (Orion, Thermo Fisher 186 Scientific, USA) after calibration against NIST buffer solutions. Redox potential was measured with 187 a platinum electrode, and values were corrected against the Zoßell's solution. ${ }^{28}$ Conductivity was 188 determined by conductivity meter (Thermo Orion 150 Aplus). Alkalinity was measured on filtered 189 aliquot using both the Gran titration method with hydrochloric acid (indicator: methyl orange), and 190 the Gran function plot method. ${ }^{29}$ Another aliquot of filtered solution was placed in acid pre-cleaned 191 polyethylene bottles and then acidified to $1 \% \mathrm{HNO}_{3}$ for subsequent analysis by

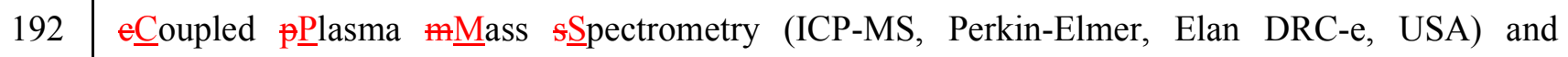

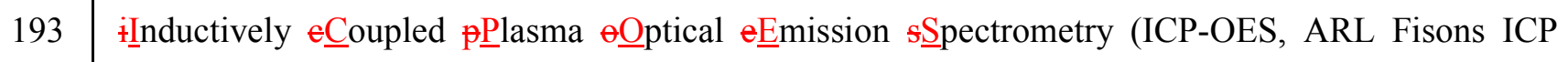

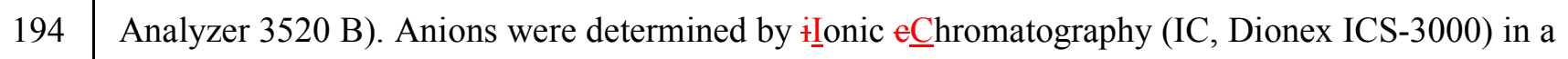
195 filtered $(0.45 \mu \mathrm{m})$ unacidified aliquot. The $\mathrm{AD}$ etection $1 \underline{\mathrm{Limit}}(\mathrm{DL})$ for chemical elements was 196 calculated at 10 times the standard deviation of the blank solutions. To evaluate the accuracy and 197 precision of trace elements determination, two reference solutions were used: the NIST SRM 1643e 
198 and the EnviroMAT Ground Water ES-L-1. Rhodium was used as an internal standard for ICP-MS

199 analysis to correct for instrument drift. The ionic balance was always better than $\pm 10 \%$.

\section{$200 \quad 2.5$ Speciation and equilibrium calculations}

201 Speciation and equilibrium calculation were performed using the PHREEQC computer program 202 (llnl database). Saturation indexes (SI) with respect to solid phases were calculated as SI $=\log$ $203\left(\mathrm{IAP} / \mathrm{K}_{\mathrm{s}}\right)$, where IAP is the ionic activity product and $\mathrm{K}_{\mathrm{s}}$ the solubility equilibrium constant at the 204 specific water temperature..$^{30}$ pe vs $\mathrm{pH}$ diagrams were plotted using the Hydra-Medusa software and 205 its internal database complex.db and complex.elb. ${ }^{31}$

206 3. Results

207 3.1 Mineralogical and microscopic characteristics before and after the carbonation 208 experiment

209 CKD was investigated by XRD (Fig. 1) and SEM analysis (Fig. 2 and 3) before and after the 24210 hour carbonation test. Raw $\mathrm{CKD}$ (Fig. 1a) are made up of calcite $\left(\mathrm{CaCO}_{3}\right)$, quartz $\left(\mathrm{SiO}_{2}\right)$, lime $211(\mathrm{CaO})$ and dolomite $\left(\mathrm{CaMg}\left(\mathrm{CO}_{3}\right)_{2}\right)$. In addition, peaks ascribed to cement minerals such as 212 portlandite $\left(\mathrm{Ca}(\mathrm{OH})_{2}\right)$ and ettringite $\left(\mathrm{Ca}_{6} \mathrm{Al}_{2}(\mathrm{SO} 4)_{3}(\mathrm{OH})_{12} \cdot 26 \mathrm{H}_{2} \mathrm{O}\right)$ were detected. Bixbyite $213\left(\mathrm{Mn}_{2} \mathrm{O}_{3}\right)$ and, likely, rankinite $\left(\mathrm{Ca}_{3} \mathrm{Si}_{2} \mathrm{O}_{7}\right)$ and gehlenite $\left(\mathrm{Ca}_{2} \mathrm{Al}_{2} \mathrm{SiO}_{7}\right)$ were also found. SEM 214 analysis (Fig. 2a) of the raw material shows that the grain size ranges from hundreds of nm to 215 hundreds of $\mu \mathrm{m}$, indicating high heterogeneity for the CKD. EDS spectra show that quartz (Fig. 2b), 216 calcite (Fig. 2c), and dolomite (Fig. 2d) can be easily recognized. Some micrometric crystals have a 217 hexagonal habitus typical of portlandite (images not shown).

218 XRD analysis of CKD after carbonation (Fig. 1b) reveals that the amount of calcite increases after 219 the experiment while lime, portlandite, ettringite, and bixbyite disappear. Besides the presence of 220 quartz, calcite, dolomite, and Ca-silicates (observed already in the raw sample), traces of gypsum 221 were detected after the carbonation experiment. Gypsum, most likely, derived from ettringite 
222 dissolution, the subsequent release of $\mathrm{Ca}^{2+}$ and $\mathrm{SO}_{4}{ }^{2-}$ ions in solution and their precipitation as 223 gypsum and calcite.

224 To reveal grain surface processes, SEM analysis was performed on CKD sections after the 225 carbonation experiment (Fig. 3a-b). Figure 3a shows the backscattered electron image, and Figures 226 from $3 \mathrm{~b}$ to $3 \mathrm{~d}$ show the energy dispersive X-ray maps for $\mathrm{Si}(\mathrm{b}), \mathrm{Ca}$ (c), and $\mathrm{Al}$ (d). Micro-analysis 227 and EDS mapping indicate that these grains consist of Ca-Al-silicates, in agreement with XRD 228 analysis (see Fig. 1b) that shows residues of gehlenite in the treated sample. After the carbonation 229 test, residual Ca-silicate grains investigated by SEM appear to be not carbonated, and enveloped by 230 a Si-rich (Fig. 3b) decalcified rim (Fig. 3c). There, Al is homogeneously distributed (Fig. 3d), and 231 elements such as $\mathrm{Fe}, \mathrm{S}, \mathrm{K}$ and $\mathrm{V}$ can be recognized by EDS analysis (data not shown).

\section{2 $\mathrm{CO}_{2}$ uptake}

234 Figure 4 shows the $\mathrm{CO}_{2}$ uptake and the $\mathrm{Ca}$ - degree of sequestration in terms of reactive species conversion yields, conversion yields-as assessed during the accelerated carbonation test. The timedependent curve shows a very fast initial conversion of $\mathrm{Ca}$ alkaline reactive species into carbonates. Then, a plateau is reached, at a value lower than the maximum theoretical $\mathrm{CO}_{2}$ sequestration 238 capacity of $13.4 \%$. As far as the potential of $\mathrm{CO}_{2}$ sequestration is concerned, the results obtained in 239 this study $\left(9.45 \%\right.$ by mass of $\left.\mathrm{CO}_{2}\right)$ are similar with those reported by Gunning et al. ${ }^{16}(9 \%$ at 240 ambient temperature and 2 bar over $72 \mathrm{~h}$ ), but lower by ca $4 \%$ with respect to maximum 241 sequestration potential observed for this material. Understanding the mechanisms underlying this 242 limit provide us a basis also for comparing the results from different experiments. 
3.3 Chemical analysis, thermodynamic driving force and saturation state of the leached

245

246

247

\section{solutions}

XRD analysis reveals that lime, portlandite, ettringite, rankinite and gehlenite are the original phases potentially involved in the carbonation process by providing cations, moving $\mathrm{pH}$ value toward slightly basic conditions thus favouring the dissolution of $\mathrm{CO}_{2}$ and dissociation of carbonic acid to eventually increase concentration of carbonate ion. Actually, the SI respect to the above mentioned minerals are negative $(<-10)$ in the liquid phase, indicating that their dissolution is favoured and, consequently, these are a source of $\mathrm{Ca}$ for the carbonation reactions.

Table 2 shows $\mathrm{pH}$, redox potential (Eh), electrical conductivity (Cond), and the concentration of selected chemical components of the liquid phase collected during the carbonation experiment. $\mathrm{pH}$, Eh and Cond values were measured immediately after solution collection from the reactor. At the same time, different aliquots were stabilized for chemical analysis. Reported values of $\mathrm{Ca}, \mathrm{Mg}$, $\underline{\mathrm{HCO}}_{3}{ }^{-}, \mathrm{SO}_{4}{ }^{2-}, \mathrm{SiO}_{2}$ and $\mathrm{Al}$ are the total concentrations of each chemical species measured as described in the paragraph 2.4. Table 3 reports PHREEQC output speciation of selected chemical species (reported as ion activity) deriving from the dissolution of portlandite, ettringite, rankinite, and gehlenite, and of the $\mathrm{HCO}_{3}{ }^{-}$and $\mathrm{CO}_{3}{ }^{2-}$ species involved in the precipitation of carbonate minerals. Trace elements are reported in Table 4. Set times $0.5,1,2,5,8$, and 24 hours will be referred to hereafter as T1, T2, T3, T4, T5 and T6, respectively. $\mathrm{pH}$ values_(Table 2) are near neutral and decrease from 7.55 to 6.79 , probably initially dominated by the fast dissolution of portlandite and ettringite, then governed by the dissolution of $\mathrm{CO}_{2}$ in water, the formation of carbonic acid and its subsequent dissociation. In addition, $\mathrm{pH}$ values $(7.11 \pm 0.07)$, observed between T3 and T6 sampling, reflect the buffering effect of calcite precipitating during accelerated carbonation. Redox potential values (Eh between 342 and $453 \mathrm{mV}$ ) indicate oxidizing conditions, and tend to increase during the experiment. 
268 Concentration of $\mathrm{Ca}$ and $\mathrm{Mg}, \mathrm{HCO}_{3}{ }^{-}$and $\mathrm{SO}_{4}{ }^{2-}$, and $\mathrm{SiO}_{2}$ and $\mathrm{Al}$ vs time in the liquid phase, 269 collected during the carbonation experiment, are shown in Fig. 5a, 5b and 5c, respectively (see also 270 Fig. S3). $\mathrm{Ca}^{2+}(60-70 \%)$ is the most abundant species (Table 3) for the total content of Ca. This 271 tends to increase in the first 2 hours, and reaches the highest concentration $(43 \mathrm{mmol} / \mathrm{l})$ at $\mathrm{T} 3$. Then, 272 it decreases from T3 to T6 $(26 \mathrm{mmol} / \mathrm{l})$. This trend is due to the release of Ca to solution because of 273 the dissolution of lime, portlandite, ettringite and $\mathrm{Ca}(\mathrm{Al})$-silicates between $\mathrm{T} 1$ and $\mathrm{T} 3$. Then, $\mathrm{Ca}$ 274 concentration decreases because of the precipitation of new phases, such as calcite and gypsum (see 275 Fig. 1 and 3.1 paragraph), or to absorption processes that become predominant over the dissolution 276 reactions between $\mathrm{T} 3$ and $\mathrm{T} 6$. In agreement, equilibrium calculation shows that calcite is 277 oversaturated in solution (Fig. 6a).

278 Mg concentration (Table 2, Fig. 5a_and Fig. S3a) increases from T1 to T6, despite results of 279 equilibrium calculation (Fig. 6b) indicate that leached solutions are oversaturated with respect to $280 \mathrm{Mg}(\mathrm{Ca})$-bearing carbonate minerals such as dolomite and magnesite. In fact, although dolomite is 281 oversaturated in studied solutions (SI between 3.1 and 5), dolomite precipitation is driven by kinetic 282 factors. A high $\mathrm{Mg}^{2+} / \mathrm{Ca}^{2+}$ molar ratio (higher than $\left.5-10: 1\right)^{32}$ is required to precipitate dolomite 283 because the $\mathrm{Mg}^{2+}$ ion has a high hydration energy ${ }^{33}$. Leached solutions have a $\mathrm{Mg}^{2+} / \mathrm{Ca}^{2+}$ molar 284 ratio between 0.10 and 0.96 , and increase from T1 to T5 (Fig. 5a and Fig. S4) because of calcite 285 precipitation, reaching steady-state values between $\mathrm{T} 5\left(\mathrm{Mg}^{2+} / \mathrm{Ca}^{2+}=0.92\right)$ and $\mathrm{T} 6\left(\mathrm{Mg}^{2+} / \mathrm{Ca}^{2+}=\right.$ 286 0.96). Moreover, the kinetic of precipitation mechanism of $\mathrm{Mg}$ carbonates is controlled by the 287 supersaturation with respect to magnesite. ${ }^{34}$ In a broad range of $\mathrm{PCO}_{2}$ and $\mathrm{Mg}^{2+} / \mathrm{Ca}^{2+}$ activity ratio 288 in solution, the composition of precipitated Ca-Mg carbonate depends only on SI respect to 289 magnesite. Under observed values ( $\mathrm{SI}<3), \mathrm{Mg}$ can be incorporated into Ca carbonate only in few 290 amount by forming low-magnesian calcite. Thus, $\mathrm{Mg}^{2+}$ ions remain in solution and do not 291 contribute to $\mathrm{CO}_{2}$ uptake during the carbonation process. Other than calcite, strontianite (Fig. 6c), 292 and witherite (Fig. 6d) are oversaturated in solution. Although XRD analysis reveals only the 293 presence of calcite, $\mathrm{Sr}$ and $\mathrm{Ba}$ carbonates could form independent phases coprecipitating with 
294 calcite, but sensitivity of XRD technique does not allow their detection. Amorphous phases cannot 295 be detected by XRD as well.

296 Alkalinity $\left(\mathrm{HCO}_{3}{ }^{-}\right)$increases from T1 to T5 (Fig. 5b and Fig. S3b), and it reaches a steady-state 297 value between T5 and T6. The observed increase in alkalinity from T1 to T5 is due to the 298 continuous dissolution of $\mathrm{CO}_{2}$ into the slurry solution and relative dissociation of carbonic acid. The 299 behaviour of $\mathrm{SO}_{4}$ can be explained considering dissolution mechanism of ettringite. Ettringite is a 300 stable mineral above a $\mathrm{pH}$ of 10.7 and dissolves congruently with a $\log \mathrm{K}_{\mathrm{sp}}$ of $-111.6( \pm 0.8)$. At 301 near neutral $\mathrm{pH}$, ettringite undergoes incongruent dissolution to gypsum, Al-hydroxides and Al302 hydroxy sulphates, thus controlling $\mathrm{Ca}^{2+}, \mathrm{Al}^{3+}$, and $\mathrm{SO}_{4}{ }^{2-}$ activities. ${ }^{35}$

$303 \mathrm{SiO}_{2}$ and $\mathrm{Al}$ have a similar trend (Fig. 5c and Fig S3c), showing an initial increase in concentration, 304 from $\mathrm{T} 1$ to $\mathrm{T} 2$, and a decrease until T6. Actually, $\mathrm{SiO}_{2}\left(\mathrm{SI}_{\text {quartz }}\right.$ 0.9-1.3), $\mathrm{Al}(\mathrm{OH})_{3}(\mathrm{SI} 2.0-2.8)$, and 305 Ca-Al-silicate hydrate minerals, such as gismondine $\left(\mathrm{Ca}_{2} \mathrm{Al}_{4} \mathrm{Si}_{4} \mathrm{O}_{16} \cdot 9 \mathrm{H}_{2} \mathrm{O}\right.$, SI 9-15), scolecite $306\left(\mathrm{CaAl}_{2} \mathrm{Si}_{3} \mathrm{O}_{10} \cdot 3 \mathrm{H}_{2} \mathrm{O}\right.$, SI 6.6-10) and laumontite $\left(\mathrm{CaAl}_{2} \mathrm{Si}_{4} \mathrm{O}_{12} \cdot 4 \mathrm{H}_{2} \mathrm{O}\right.$, SI 5.7-9.5) are oversaturated in 307 solution. Moreover, precipitation of Ca-silicate hydrate gel occurs, as observed by SEM analysis.

308 Trace elements behave according to two distinct groups: 1) V, Mo, Li, B, Ni, U and Sb show an 309 increase in concentration during the experiment; 2) Rb, Ba, Cr, Sr, $\mathrm{Zn}, \mathrm{Mn}, \mathrm{Cd}, \mathrm{Co}, \mathrm{Tl}$, and As are 310 released immediately in solution and then decrease during the carbonation experiment. The 311 available literature studies focusing on the influence of MC on trace element solubility indicate that 312 carbonation could either increase or reduce trace element mobility from alkaline residues. ${ }^{36,37}$ In 313 particular, an higher release has been observed for oxyanions, according to the fact that they are 314 often incorporated in ettringite-like minerals which dissolve upon carbonation. Other elements such 315 as heavy metals are converted into their less soluble salts or immobilized through sorption onto $316 \mathrm{CaCO}_{3}$ and/or co-precipitation into newly formed minerals. 


\section{4. Discussion}

$319 \quad 4.1$ Process chemistry and thermodynamic prediction

320 To investigate mineralogical processes of dissolution and precipitation governing accelerated 321 carbonation of CKD, we combined chemical data with PHREEQC calculations, XRD and SEM 322 analysis. During the carbonation test, injected $\mathrm{CO}_{2}$ dissolves into solution proportionally to the $323 \mathrm{PCO}_{2}$, in accordance with Henry's law, and hydrates to carbonic acid $\left(\mathrm{H}_{2} \mathrm{CO}_{3}\right)$. Then $\mathrm{H}_{2} \mathrm{CO}_{3}$ 324 dissociates into bicarbonate $\left(\mathrm{HCO}_{3}{ }^{-}\right)$and carbonate $\left(\mathrm{CO}_{3}{ }^{2-}\right)$ ions depending on the solution $\mathrm{pH}$. 325 Simultaneously, phases such as lime and portlandite (Fig. 1a) in contact with water undergo fast 326 dissolution, in agreement with the calculated SI $(<-10)$, leading to a fast increase in $\mathrm{Ca}^{2+}$ 327 concentration from T1 to T2 (see Table 2 and Fig. 5a). As indicated by the activity values in Table $3283, \mathrm{Ca}^{2+}$ aquo ions react with $\mathrm{CO}_{3}{ }^{2-}$ leading to calcite bulk precipitation from solution.

329 Also, ettringite, ${ }^{38,39}$ rankinite and gehlenite ${ }^{2}$ take part to the carbonation process. During ettringite 330 dissolution, $\mathrm{Ca}^{2+}$ and $\mathrm{SO}_{4}{ }^{2-}$ ions are released into solution and then precipitate as gypsum and 331 calcite. In agreement, XRD peaks of gypsum were observed in the carbonated CKD sample (Fig. $3321 b)$

333 Transformation of Ca-silicates to Ca-carbonate is characterized by a slower dissolution kinetics of 334 Ca-silicates than lime and portlandite. SEM analysis (see Fig. 3) shows that the residual non335 carbonated grains of Ca-Al-silicates are surrounded by a Si-rich decalcified rim. This can be 336 explained considering that carbonation of $\mathrm{Ca}$ silicates is accompanied by hydration ${ }^{36}$ that leads to $^{2}$ 337 the precipitation of a Ca-silicate hydrate gel. During the carbonation process, the Ca-silicate hydrate 338 gel is progressively decalcified. ${ }^{4}$ Accordingly, the $\mathrm{Ca}^{2+} / \mathrm{SiO}_{2}{ }^{0}$ activity ratio increase in the liquid 339 phase (Fig. 7 and Fig. S3) due to the release of $\mathrm{Ca}^{2+}$ ions which become available for calcite 340 precipitation. It was demonstrated ${ }^{2,41}$ that, progressively, the Ca-silicate hydrate gel is transformed 341 into calcite and highly polymerized silicate gel. This process is the so called secondary 
342 carbonation, ${ }^{36}$ but, being a slow solid state diffusion process, it has limited practical effect for 343 carbonation purposes.

344 Figures 8a and $\mathrm{b}$ show predominance Pourbaix diagrams for the system Ca-Al-C-Si-H-O, plotted 345 considering chemical parameters from speciation calculation for $\mathrm{T} 1$ and $\mathrm{T} 6$ samplings. 346 Predominance diagrams allow having a synoptic view of physico-chemical evolution of the 347 investigated system and prediction of mineral evolution. It is worth noting that, in Fig. 8, the $\mathrm{CaCO}_{3}$ 348 stability field increases in time from T1 to T6 indicating conditions more favourable to calcite 349 precipitation. Concomitantly, the stability field of $\mathrm{CaSiO}_{3}$ disappears in favour of the $\mathrm{Ca}_{2} \mathrm{SiO}_{4}$ field, 350 corresponding to a decrease of Si activity in solution (see Table 3 ) that, in turn, likely favours Si 351 storage in amorphous grain coatings. Black circles indicate $\mathrm{pH}$ and pe values of the collected liquid 352 phase at T1 (Fig. 8a) and T6 (Fig. 8b). Although black circles fall outside the calcite field, it is 353 worth nothing that chemical properties of the liquid film in contact with the alkaline solid waste 354 grains are different from that of the bulk solution. In fact, dissolution of minerals such as lime, 355 portlandite, gehlenite and rankinite leads to the consumption of hydrogen ions and, consequently, to 356 an increase in $\mathrm{pH}$ values, especially in the solution in contact with mineral grains.

\section{$358 \quad 4.2$ Reaction pathways and chemical processes affecting $\mathrm{CO}_{2}$ uptake}

359 The rate and extent of carbonation of CKD is affected by transport-controlled mechanisms such as $360 \mathrm{CO}_{2}$ and $\mathrm{Ca}^{2+}$ diffusion to/from reaction sites, boundary layer effects (diffusion across precipitate 361 coatings on particles), dissolution of $\mathrm{Ca}(\mathrm{OH})_{2}$ at the particle surface, and pore blockage or 362 precipitate coating development. ${ }^{22}$ Huntzinger et al. ${ }^{22}$ studied the extent and potential mechanisms 363 and rate behaviour of the carbonation process in CKD at ambient temperatures and pressures by 364 applying X-ray spectrometry, XRD, thermal analysis, and observed dry mass change. The major 365 reactive $\mathrm{Ca}$ species identified in $\mathrm{CKD}$ samples before carbonation experiments were lime and 366 portlandite. Authors ${ }^{22}$ stated that $\mathrm{CO}_{2}$ sequestration appears to follow unreacted core model theory. 
367 As carbonation progresses, the kinetics of the reaction are attenuated by the extent of the reaction 368 due to diffusion control, with the extent of conversion never reaching completion. Anderson et $369 \mathrm{al}^{24,42}$ investigated the reaction pathways ruling the carbonation processes in CKD by 370 environmental SEM, XRD, thermal gravimetric analysis/differential thermal analysis. PHREEQC 371 was used for modelling CKD reaction using a 10:1 liquid to solid ratio, and a simplified 372 composition of CKD. Authors ${ }^{24,42}$ found that lime and portlandite were the major reactants. A 373 second reaction path was the weathering of $\mathrm{Ca}$-silicates that released $\mathrm{Ca}^{2+}$ for carbonation. Three 374 types of $\mathrm{CaCO}_{3}$ precipitation mechanisms were observed: (1) diffusion of $\mathrm{CO}_{2}$ into portlandite 375 particles causing precipitation in the pores of the particle and the growth of a $\mathrm{CaCO}_{3}$ skin from the 376 outside inward, slowing vapor and aqueous diffusion by causing blockages in the pore systems, (2) 377 precipitation onto existing particles, and (3) precipitation from aqueous solution.

378 In this study, we combined XRD_and- SEM-EDS analysis performed before and after the 379 carbonation experiment, and-with solution chemistry ${ }_{2}$ with_speciation and equilibrium calculations 380 performed at each set time $(0.5,1,2,3,5,8$ and 24 hours $)$ to better investigate chemical processes 381 limiting $\mathrm{CO}_{2}$ uptake. According to mineralogical and chemical investigations, we propose that the 382 investigated accelerated carbonation of CKD follows a pathway of dissolution and precipitation 383 reactions:

384 1. hydration and/or dissolution of lime, portlandite, and ettringite and release of $\mathrm{Ca}^{2+}$ ions in 385 solution:

$$
\mathrm{CaO}_{(\mathrm{s})}+\mathrm{H}_{2} \mathrm{O} \leftrightarrow \mathrm{Ca}(\mathrm{OH})_{2(\mathrm{~s})}
$$$$
\mathrm{Ca}(\mathrm{OH})_{2(\mathrm{~s})} \leftrightarrow \mathrm{Ca}^{2+}+2 \mathrm{OH}^{-}
$$$$
\mathrm{Ca}_{6}\left[\mathrm{Al}(\mathrm{OH})_{6}\right]_{2}\left(\mathrm{SO}_{4}\right)_{3} \cdot 26 \mathrm{H}_{2} \mathrm{O} \leftrightarrow 6 \mathrm{Ca}^{2+}+2 \mathrm{Al}(\mathrm{OH})_{4}{ }^{-}+3 \mathrm{SO}_{4}{ }^{2-}+4 \mathrm{OH}^{-}+26 \mathrm{H}_{2} \mathrm{O}
$$

2. partial dissolution of rankinite and gehlenite, release of $\mathrm{Ca}^{2+}$ ions in solution and formation of a $\mathrm{Ca}(\mathrm{Al})$-silicate external rim: 
393 3. contemporary dissolution of gaseous $\mathrm{CO}_{2}$ into solution and formation of bicarbonate ions 394 according to the observed $\mathrm{pH}$ values (7.2 \pm 0.2$)$ : $\mathrm{CO}_{2}+\mathrm{H}_{2} \mathrm{O} \leftrightarrow \mathrm{H}^{+}+\mathrm{HCO}_{3}^{-}$

In a first stage, a rapid transformation of lime, portlandite and ettringite into Ca-carbonate takes 403 place. After their consumption, $\mathrm{Ca}$ from the $\mathrm{Ca}-(\mathrm{Al})$-silicate phases diffuses toward the surface of 404 the grains, and $\mathrm{Ca}^{2+}$ ions are dissolved into solution and precipitated as calcite. Leaching of $\mathrm{Ca}$ from $405 \mathrm{Ca}-(\mathrm{Al})$-silicates results in a withdrawing $\mathrm{Ca}-(\mathrm{Al})$-silicate core covered by a Si-rich decalcified rim 406 (see Fig. 3) that may change the rate and mechanism of dissolution. During decalcification of the 407 external rim, $\mathrm{Ca}^{2+}$ ions are dissolved into solution, while Si remains in the solid state, hindering the 408 diffusion of $\mathrm{Ca}^{2+}$ ions from the grain core, and limiting conversion. ${ }^{20,41}$ Indeed, XRD analysis (see 409 Fig. 1b) show that Ca silicate grains are still present in carbonated CKD, because formation of the 410 external rim results in diffusion to be the rate limiting step, then limiting the carbonation process. 411 This is reflected in the time-dependent curve of $\mathrm{CO}_{2}$ uptake in Fig. 4 that shows an exponential 412 shape, suggesting an initial rapid conversion of $\mathrm{Ca}$ reactive species into carbonates, and a 413 subsequent decrease in reaction rate without reaching a complete conversion as estimated by the 414 maximum theoretical $\mathrm{CO}_{2}$ sequestration capacity (13.4\%). This behaviour indicates that carbonation 415 process follows an "unreacted core model". ${ }^{22,40}$ Moreover, in our slurries experiments the rim is not 416 made of calcite, as observed by Anderson $^{42}$, the latter mineral precipitating from bulk solution. 417 Thus, we argued that the rim hindering the unreacted core appears to be dependent on the 418 experimental condition. Specifically, the composition of the rim could depend on the composition 
419 of the given CKD and also on the liquid-solid ratio. Moreover, CKD material comprise several 420 minerals whose relative abundance is not constant. These findings allow us to assert that a potential 421 optimization of the $\mathrm{CO}_{2}$ uptake by $\mathrm{CKD}$ could be achieved properly selecting specific additives ${ }^{43}$ to 422 hinder the formation of external layers for improving diffusion of $\mathrm{Ca}$ ions through the Ca-Al-silicate 423 grains to enhance carbonation reaction of the unreacted particle core.

\section{5. Conclusions}

425 The carbonation of $\mathrm{CKD}$ has been proved to be an effective technology to capture $\mathrm{CO}_{2}$, and it need 426 to be improved for being applied at a commercial scale. To reach the highest sequestration capacity, 427 the main goals are represented by the identification of the optimal operating parameters and the 428 limiting reaction mechanisms. In order to achieve a better understanding of the chemical and 429 mineralogical processes affecting carbonation and $\mathrm{CO}_{2}$ uptake efficiency of $\mathrm{CKD}$, a slurry-phase 430 accelerated carbonation was performed at $25^{\circ} \mathrm{C}$ and 3 bar. The $\mathrm{CO}_{2}$ uptake by $\mathrm{CKD}$ follows an 431 exponential increase, achieving a carbonation capacity of $9.45 \%$ in the first hour. XRD analysis 432 indicates that the reactive species in CKD are lime, portlandite, ettringite, rankinite, and gehlenite. 433 Direct observations by XRD and SEM, and geochemical modelling of solution in contact with CKD 434 during the carbonation experiment indicate that $\mathrm{CO}_{2}$ uptake is limited by the formation of a Si-rich 435 decalcified layer covering the residual Ca-Al-silicates grains. In fact, in the presence of the Si-rich 436 decalcified layer, the solution chemistry reached a stationary state and carbonation ceased before 437 reaching the maximum theoretical uptake (13.4\%). Literature studies on CKD observed the 438 formation of a rim made of calcite instead of a Si-rich decalcified layer. Thus, we argued that the 439 knowledge of the specific mechanism active in a given CKD carbonation set-up (reactor and 440 materials) has direct implication for the scaling up to pilot or pre-industrial scale experiment. The 441 findings from the present study indicate that a further process optimization is possible, aimed at 442 avoiding the formation of Si-rich decalcified layer. On the basis of the $\mathrm{CO}_{2}$ sequestration capacity 443 of $9.45 \%$ assessed during the present study, since 0.2 tons of CKD for every ton of clinker are 
444 produced $^{17}$ and 0.507 tons of $\mathrm{CO}_{2} /$ ton of clinker are emitted, ${ }^{44}$ the carbonation treatment would 445 have the potential for sequestering $3.7 \%$ of the cement plant $\mathrm{CO}_{2}$ emissions, which would increase 446 to up to $5.27 \%$ if the maximum theoretical $\mathrm{CO}_{2}$ sequestration capacity of $13.4 \%$ is exploited. This 447 increase of carbonation efficiency is a crucial aspect in lowering the industrial capture cost, which is 448 still considered too high for the implementation of MC on a large scale. Further studies with slurry 449 accelerated carbonation of $\mathrm{CKD}$ would be useful in order to define the optimal conditions for 450 enhanced carbonation process also by using additives to hinder silica rim formation.

\section{Acknowledgements}

453 This work was funded by RAS grant CRP 25 659. The authors acknowledge two anonymous 454 reviewers greatly for their useful comments, and the Managing Editor, Sarah Watson, for the 455 manuscript handling.

\section{References}

458 1. Nyambura MG, Mugera GW, Felicia, PL and Gathura NP. Carbonation of Brine Impacted Fractionated Coal Fly Ash: Implications for $\mathrm{CO}_{2}$ Sequestration. J Environ Manage 92(3): 655-664 (2011).

2. Pan SY, Chang EE and Chiang PC. $\mathrm{CO}_{2}$ capture by accelerated carbonation of alkaline wastes: A review on its principles and applications. Aerosol Air Qual Re. 12: 770-791 (2012).

3. Seifritz W. $\mathrm{CO}_{2}$ Disposal by Means of Silicates. Nature 345 (6275): 486-486 (1990).

4. Lackner KS. Carbonate chemistry for sequestering fossil carbon. Annu Rev Energy Environ 27: 193-232 (2002).

5. Rau G. $\mathrm{CO}_{2}$ Mitigation via Capture and Chemical Conversion in Seawater. Environ Sci Technol 45(3): 1088-1092 (2011). 
469 6. Galan I, Andrade $\mathrm{C}$ and Castellote $\mathrm{M}$. Natural and accelerated $\mathrm{CO}_{2}$ binding kinetics in $470 \quad$ cement paste at different relative humidities. Cem Concr Res 49: 21-28 (2013).

471 7. Muduli SD, Nayak BD, Dhal NK and Mishra BK. Atmospheric $\mathrm{CO}_{2}$ Sequestration through 472 Mineral Carbonation of Fly Ash. Greener Journal of Physical Sciences 4: 273-278 (2014).

473 8. Lim M, Han GC, Ahn JW and You KS. Environmental Remediation and Conversion of 474 Carbon Dioxide $\left(\mathrm{CO}_{2}\right)$ into Useful Green Products by Accelerated Carbonation Technology. 475 Int J Environ Res, Public Health 7(1): 203-228 (2010).

476 9. Renforth P, Washbourne CL, Taylder J and Manning DAC. Silicate Production and 477 Availability for Mineral Carbonation. Environ Sci Technol 45(6): 2035-2041(2011).

478 10. Sanna A, Uibu, M, Caramanna, G, Kuusik, R and Maroto-Valer, MM. A Review of Mineral 479 Carbonation Technologies to Sequester $\mathrm{CO}_{2}$. Chem Soc Rev 43: 8049-8080 (2014).

480 11. Pan SY, Chiang A, Chang EE, Lin YP, Kim H and Chiang PC. An innovative approach to 481 integrated carbon mineralization and waste utilization: a review. Aerosol Air Qual Res 15: $482 \quad$ 1072-1091(2015).

483 12. Zevenhoven R, Fagerlund J and Songok JK. $\mathrm{CO}_{2}$ mineral sequestration: developments $484 \quad$ toward large scale application. Greenhouse Gases Sci Technol 1: 48-57 (2011).

485 13. Huijgen WJJ, Witkamp GJ and Comans RNJ. Mineral $\mathrm{CO}_{2}$ sequestration by steel slag $486 \quad$ carbonation. Environ Sci Technol 39 (24): 9676-9682 (2005).

487 14. Ukwattage NL, Ranjith PG, Yellishetty M, Bui HH and Xu T. A laboratory-scale study of 488 the aqueous mineral carbonation of coal fly ash for $\mathrm{CO}_{2}$ sequestration. $J$ Clean Prod 103: $489 \quad 665-674(2015)$.

490 15. Azdarpour A, Asadullah M, Mohammadian E, Hamidi H, Junin R and Karaei MA. A review 491 on carbon dioxide mineral carbonation through pH-swing process. Chem Eng J, 279: 615$492630(2015)$.

493 16. Gunning PJ, Hills CD and Carey PJ. Accelerated carbonation treatment of industrial wastes. 494 Waste Manage 30(6): 1081-1090 (2010). 
495 17. Bobicki ER, Liu Q, Xu Z and Zeng H. Carbon capture and storage using alkaline industrial $496 \quad$ wastes. Prog. Energy Combust Sci 38(2): 302-320 (2012).

497 18. Sreekrishnavilasam A, King S and Santagata M. Characterization of fresh and landfilled 498 cement kiln dust for reuse in construction applications. Eng Geol 85(1-2): 165-173 (2006).

499 19. Van Oss HG and Padovani AC. Cement manufacture and the environment, Part II: $500 \quad$ environmental challenges and opportunities. J Ind Ecol 7(1): 93-127 (2003).

501 20. Olajire AA. A review of mineral carbonation technology in sequestration of $\mathrm{CO}_{2} . J$ Petrol $502 \quad$ Sci Eng 109: 364-392 (2013).

503 21. Huntzinger DN, Gierke JS, Sutter LL, Kawatra SK and Eisele TC. Mineral carbonation for 504 carbon sequestration in cement kiln dust from waste piles. J Hazard Mater 168(1): 31-37 $505 \quad$ (2009).

506 22. Huntzinger DN, Gierke JS, Kawatra SK, Eisele TC and Sutter LL. Carbon Dioxide 507 Sequestration in Cement Kiln Dust through Mineral Carbonation. Environ Sci Technol 508 43(6): 1986-1992 (2009).

509 23. Ramme BW, Naik TR and Kraus RN. An Investigation of $\mathrm{CO}_{2}$ Sequestration Through 510 Mineralization. 2nd International Conference on Sustainable Construction Materials and 511 Technologies, Ancona, Italy, 28 - 30 June (2010).

512 24. Anderson CP, Sutter LL, Huntzinger DN and Gierke JS. Effects of carbonation on the 513 mineral composition of cement kiln dust. In International Cement Microscopy Association 514 29th International Conference on Cement Microscopy, 441-470 (2007).

515 25. Cappai G, Carucci A, De Giudici G, Medas D, Muntoni A, Orru G and Piredda M. Carbon 516 dioxide sequestration by accelerated carbonation of cement kiln dust (CKD). Sardinia 2013, 517 14th International Waste Management and Landfill Symposium., S. Margherita di Pula 518 (CA), Italy, 30th September-4th October (2013).

519 26. Ali MAM and Yang HS. Utilization of Cement Kiln Dust in industry Cement Bricks. $520 \quad$ Geosystem Eng 14(1): 29-34 (2011). 
521 27. Steinour HH. Some Effects of Carbon Dioxide on Mortars and Concrete - A Discussion. J. 522 Am. Concr. Inst., 55(2): 905-907 (1959).

523 28. Nordstrom DK. Thermochemical redox equilibria of ZoBell's solution. Geochim 524 Cosmochim Acta 41(12): 1835-1841 (1977).

525 29. Gran G. Determination of the equivalence 681 point in potentiometric titrations. Acta Chem $526 \quad$ Scand 4: 559-577 (1950).

527 30. Parkhurst DL and Appelo CAJ. User's guide to PHREEQC (version 2) - A computer 528 program for speciation, batch-reaction, one-dimensional transport, and inverse geochemical 529 calculations. U.S. Geol. Surv. Water-Resour. Invest. Rep. 99-4259 (1999).

530 31. Puigdomènech I. HYDRA-MEDUSA (Make Equilibrium Diagrams Using Sophisticated 531 Algorithms). Windows interface to the MS-DOS versions of INPUT, SED and PREDOM 532 (FORTRAN programs drawing chemical equilibrium diagrams) Vers. 6 December 2010. 533 Royal Institute of Technology (KTH), Stockholm.

534 32. Folk R and Land L. Mg/Ca ratio and salinity: two controls over crystallization of dolomite. 535 Am Assoc Pet Geol Bull 59: 60-68 (1975).

536 33. Xu J, Yan C, Zhang F, Konishi H, Xu H and Tenga HH. Testing the cation-hydration effect 537 on the crystallization of Ca-Mg-CO3 systems. Proc Natl Acad Sci U S A. 110(44):17750-5 $538 \quad(2013)$

539 34. Prigiobbe V, Hänchen M, Werner M, Baciocchi R, and Mazzotti M. Mineral carbonation 540 process for $\mathrm{CO}_{2}$ sequestration, $9^{\text {th }}$ International Conference on Greenhouse Gas Control $541 \quad$ Technologies, Energy Procedia 1, 4885-4890(2009)

542 35. Mynenia SCB, Trainaa SJ, and Logana TJ. Ettringite solubility and geochemistry of the $543 \mathrm{Ca}(\mathrm{OH})_{2}-\mathrm{Al}_{2}\left(\mathrm{SO}_{4}\right)_{3}-\mathrm{H}_{2} \mathrm{O}$ system at 1 atm pressure and $298 \mathrm{~K}$. Chem Geol 148(1-2):1-19 $544 \quad(1998)$ 
545 36. Bertos MF, Simons SJR, Hills CD and Carey PJ. A review of accelerated carbonation 546 technology in the treatment of cement-based materials and sequestration of $\mathrm{CO}_{2} . J$ Hazard 547 Mater 112(3): 193-205 (2004).

548 37. Cappai G, Cara S, Muntoni A, Piredda M. Application of accelerated carbonation on MSW 549 combustion APC residues for metal immobilization and $\mathrm{CO}_{2}$ sequestration. $J$ Hazard Mater, 550 207-208: $159-164$ (2012).

551 38. Nishikawa T, Suzuki K, Ito S, Sato K and Takebe T. Decomposition of synthesized 552 ettringite by carbonation. Cem Concr Res 22(1): 6-14 (1992).

553 39. Lange LC, Hills CD and Poole AB. Preliminary investigation into the effects of 554 carbonations on cement - solidified hazardous wastes. Environ Sci Technol 30(1): 5-30 $555 \quad(1996)$

556 40. Huijgen WJJ and Comans RNJ. Mineral $\mathrm{CO}_{2}$ sequestration by carbonation of industrial 557 residues. Literature review and selection of residue ECN-C-05-074 (2005).

558 41. Thiery M, Villain G, Dangla P and Platret G. Investigation of the Carbonation front Shape 559 on Cementitious Materials: Effects of the Chemical Kinetics. Cem Concr Res 37(7): 1047$5601058(2007)$.

561 42. Anderson CP. Effects of carbonation on the mineral composition of cement kiln dust, $562 \quad$ Master's Thesis, Michigan Technological University (2006).

563 43. Bonfils B, Bourgeois F, Julcour-Lebigue C, Guyot F and Chiquet P. Understanding the 564 Chemistry of Direct Aqueous Carbonation with Additives Through Geochemical Modelling. 565 Energy Procedia, 10th International Conference on Greenhouse Gas Control Technologies, 566 2011, vol. 4. pp. 3809-3816.

567 44. IPCC - Intergovernmental Panel on Climate Change. Revised 1996 IPCC Guidelines for 568 National Greenhouse Gas Inventories. Reference Manual (Revised). Vol 3. J.T. Houghton et 569 al., IPCC/OECD/IEA, Paris, France (1997). 
571 Figure 1. XRD pattern of CKD before (a) and after the carbonation test (b). Cal (calcite), Qz (quarz), Lime (lime), Dol

572 (dolomite), Prt (portlandite), Ettr (ettringite), Bix (bixbyite), Rank (rankinite), Gh (gehlenite), Gyps (gypsum).

573

574

Figure 2. Scanning eElectron mMicroscopy analysis of raw CKD. a) Overview of the CKD sample grain size; b) image and microanalysis of a quartz grain; c) image and microanalysis of a calcite grain; d) image and microanalysis of a dolomite grain.

Figure 3. Scanning Electron MicroscopySEM analysis of a CKD section after the carbonation experiment (T6). Backscattered electron image (a) and the results of $\mathrm{Si}(\mathrm{b}), \mathrm{Ca}(\mathrm{c})$, and $\mathrm{Al}$ (d) mapping by energy dispersive X-ray on the CKD sample. Arrows indicate the Si-rich decalcified rim that envelops the residual non-carbonated grains of Ca-Al-silicates.

Figure 4. $\mathrm{CO}_{2}$ uptake and degree of sequestration in terms of reactive species the Ca-conversion yields during the accelerated carbonation test.

Figure 5. Coneentration-Mean concentration of $\mathrm{Ca}, \mathrm{Mg}(\mathrm{a}), \mathrm{HCO}_{3}, \mathrm{SO}_{4}(\mathrm{~b}), \mathrm{SiO}_{2}$ and $\mathrm{Al}$ (c) vs time in the liquid phase. Also, $\mathrm{Mg}^{2+} / \mathrm{Ca}^{2+}$ molar ratio is shown.

Figure 6. SI respect to calcite and $\mathrm{Ca}^{2+}$ activity vs time (a); SI respect to dolomite, huntite, magnesite and $\mathrm{Mg}^{2+}$ activity vs time (a); SI respect to strontianite and $\mathrm{Sr}^{2+}$ activity vs time (a); SI respect to witherite and $\mathrm{Ba}^{2+}$ activity vs time (a) in the liquid phase.

Figure 7. Mean $\mathrm{Ca}^{2+} / \mathrm{SiO}_{2}{ }^{0}$ activity ratio concentration vs time in the liquid phase.

Figure 8. pe vs pH diagrams for the system Ca-Al-C-Si-H-O for liquid phase collected at T1 (a) and T6 (b). Diagrams are drawn by the chemical equilibrium-diagram-tool Hydra/Medusa. Black circles indicate pH and pe values of the collected liquid phase at $\mathrm{T} 1$ (a) and $\mathrm{T} 6$ (b). Concentrations for $\mathrm{Ca}^{2+}-\mathrm{Al}^{3+}-\mathrm{CO}_{3}{ }^{2-}-\mathrm{H}_{4} \mathrm{SiO}_{4}{ }^{0}$ come from speciation calculation performed by PHREEQC. 
602 Table 1. Elemental composition of the CKD (from Cappai et al. ${ }^{25}$ )

\begin{tabular}{|c|c|c|c|}
\hline Element & $(\%)$ & Element & $(\mathrm{mg} / \mathrm{kg})$ \\
\hline $\mathrm{Al}_{2} \mathrm{O}_{3}$ & $2.95 \pm 0.05$ & As & $16.12 \pm 0.79$ \\
\hline $\mathrm{CaO}$ & $46.75 \pm 0.91$ & $\mathrm{Ba}$ & $185 \pm 9$ \\
\hline $\mathrm{Fe}_{2} \mathrm{O}_{3}$ & $1.94 \pm 0.05$ & $\mathrm{Cd}$ & $7.08 \pm 1.22$ \\
\hline $\mathrm{K}_{2} \mathrm{O}$ & $1.30 \pm 0.01$ & Co & $5.66 \pm 0.89$ \\
\hline $\mathrm{MgO}$ & $2.64 \pm 0.08$ & $\mathrm{Cr}$ & $22.12 \pm 1.34$ \\
\hline $\mathrm{MnO}$ & $0.05 \pm 0.00$ & $\mathrm{Cu}$ & $163 \pm 9$ \\
\hline $\mathrm{Na}_{2} \mathrm{O}$ & $0.28 \pm 0.10$ & Mo & $38.87 \pm 3.13$ \\
\hline $\mathrm{P}_{2} \mathrm{O}_{5}$ & N.D. & $\mathrm{Ni}$ & $97.02 \pm 9.59$ \\
\hline $\mathrm{SiO}_{2}$ & $18.65 \pm 0.21$ & $\mathrm{~Pb}$ & $463 \pm 28.0$ \\
\hline $\mathrm{TiO}_{2}$ & $0.12 \pm 0.01$ & $\mathrm{Sb}$ & $6.82 \pm 1.13$ \\
\hline \multirow[t]{2}{*}{ LOI } & $26.80 \pm 0.10$ & $\mathrm{Se}$ & $13.31 \pm 0.10$ \\
\hline & $x_{2}$ & $\mathrm{Tl}$ & $24.87 \pm 1.10$ \\
\hline Soluble anions & $(\mathrm{mg} / \mathrm{kg})$ & $\mathrm{V}$ & $363 \pm 7$ \\
\hline Cloride & $3204 \pm 93$ & $\mathrm{Zn}$ & $177 \pm 10$ \\
\hline
\end{tabular}

603

604

605

606

607

608

609

610

611

612

613

614 
1

2

3

4

5

6

7

8

9

10

11

12

13

14

15

16

17

18

19

20

21

22

23

24

25

26

27

28

29

30

31

32

33

34

35

36

37

38

39

40

41

42

43

44

45

46

47

48

49

50

51

52

53

54

55

56

57

58

59

60

615 Table 2. Mean values of $\mathbf{p H}$, redox potential (Eh), electrical conductivity (Cond), and mean concentration of selected chemical

616 components of the liquid phase collected during the carbonation experiments.

\begin{tabular}{|c|c|c|c|c|c|c|c|c|c|c|}
\hline Sample & $\begin{array}{l}\text { Time } \\
\text { (hour) }\end{array}$ & pH & $\begin{array}{c}\mathbf{E h} \\
(\mathrm{mV})\end{array}$ & $\begin{array}{c}\text { Cond } \\
(\mathrm{mS} / \mathrm{cm})\end{array}$ & $\mathrm{Ca}$ & Mg & $\begin{array}{l}\mathrm{HCO}_{3} \\
(\mathrm{mmol} / \mathrm{l}\end{array}$ & $\mathrm{SO}_{4}$ & $\mathrm{SiO}_{2}$ & $\begin{array}{c}\mathbf{A l} \\
(\mu \mathrm{mol} / \mathrm{l})\end{array}$ \\
\hline CKD T1 & 0.5 & 7.55 & 342 & 6.8 & 22 & 3 & 14 & 31 & 3.8 & 23 \\
\hline CKD T2 & 1 & 6.79 & 374 & 7.7 & 40 & 11 & 60 & 34 & 4.5 & 30 \\
\hline CKD T3 & 2 & 7.18 & 369 & 9.1 & 43 & 19 & 81 & 34 & 3.7 & 16 \\
\hline CKD T4 & 5 & 7.04 & 425 & 9 & 37 & 26 & 93 & 29 & 2.4 & 5 \\
\hline CKD T5 & 8 & 7.05 & 451 & 8 & 28 & 30 & 103 & 23 & 2 & 4 \\
\hline CKD T6 & 24 & 7.18 & 453 & 10.3 & 26 & 36 & 106 & 25 & 1.6 & 2 \\
\hline
\end{tabular}

617

618

619

620

621

622

623

624

625

626

627

628

629

630

631

632

633

634

635

636

https://mc.manuscriptcentral.com/ghg-wiley 
637 Table 3. Activity-Mean activity of $\mathrm{Ca}^{2+}, \mathrm{HCO}_{3}{ }^{-}, \mathrm{CO}_{3}{ }^{2-}, \mathrm{SiO}_{2}{ }^{0}, \mathrm{SO}_{4}{ }^{2-}$ and $\mathrm{Al}^{3+}$ in the liquid phase collected during the 638 carbonation experiment calculated by PHREEQC.

\begin{tabular}{|c|c|c|c|c|c|c|c|}
\hline \multirow[t]{2}{*}{ Sample } & Time & $\mathrm{Ca}^{2+}$ & $\mathrm{HCO}_{3}^{-}$ & $\mathrm{CO}_{3}{ }^{2-}$ & $\mathrm{SiO}_{2}{ }^{0}$ & $\mathrm{SO}_{4}^{-2}$ & $\mathbf{A l}^{3+}$ \\
\hline & (hour) & \multicolumn{6}{|c|}{$(\mathrm{mol} / \mathrm{l})$} \\
\hline CKD T1 & 0.5 & $5.66 \mathrm{E}-03$ & $9.20 \mathrm{E}-03$ & $1.40 \mathrm{E}-05$ & $1.78 \mathrm{E}-03$ & 7.50E-03 & $8.30 \mathrm{E}-13$ \\
\hline CKD T2 & 1 & $9.10 \mathrm{E}-03$ & $3.90 \mathrm{E}-02$ & $1.10 \mathrm{E}-05$ & $2.12 \mathrm{E}-03$ & $6.20 \mathrm{E}-03$ & $1.00 \mathrm{E}-10$ \\
\hline CKD T3 & 2 & $9.48 \mathrm{E}-03$ & $5.00 \mathrm{E}-02$ & $3.40 \mathrm{E}-05$ & $1.77 \mathrm{E}-03$ & $5.50 \mathrm{E}-03$ & $9.70 \mathrm{E}-12$ \\
\hline CKD T4 & 5 & 8.11E-03 & $5.80 \mathrm{E}-02$ & $2.80 \mathrm{E}-05$ & $1.14 \mathrm{E}-03$ & 4.60E-03 & $1.60 \mathrm{E}-11$ \\
\hline CKD T5 & 8 & $6.22 \mathrm{E}-03$ & $6.50 \mathrm{E}-02$ & 3.20E-05 & $9.59 \mathrm{E}-04$ & 3.70E-03 & $1.20 \mathrm{E}-11$ \\
\hline CKD T6 & 24 & $5.66 \mathrm{E}-03$ & $6.60 \mathrm{E}-02$ & 4.40E-05 & 7.39E-04 & $3.90 \mathrm{E}-03$ & $1.80 \mathrm{E}-12$ \\
\hline
\end{tabular}

639

640

641

642

643

644

645

646

647

648

649

650

651

652

653

654

655

656

657

658

659

660

661

662

663

664

665

https://mc.manuscriptcentral.com/ghg-wiley 
2

3

4

5

6

7

8

9

10

11

12

13

14

15

16

17

18

19

20

21

22

23

24

25

26

27

28

29

30

31

32

33

34

35

36

37

38

39

40

41

42

43

44

45

46

47

48

49

50

51

52

53

54

55

56

57

58

59

60

666 Table 4. Concentration-Mean concentration of trace elements of the liquid phase collected during the carbonation 667 experiment.

668

\begin{tabular}{|c|c|c|c|c|c|c|c|c|c|c|c|c|c|c|c|c|c|c|c|c|}
\hline Sample & $\begin{array}{l}\text { Time } \\
\text { (hour) }\end{array}$ & $\mathrm{V}$ & $\mathrm{Rb}$ & $\mathrm{Sr}$ & Mo & $\mathrm{B}$ & $\mathrm{Li}$ & $\mathrm{Ba}$ & $\mathrm{Mn}$ & $\mathrm{Zn}$ & $\mathrm{Cd}$ & $\begin{array}{c}\mathrm{Cr} \\
(\mu \mathrm{mol})\end{array}$ & Co & $\mathrm{Ni}$ & $\mathrm{Pb}$ & $\mathrm{Tl}$ & U & $\mathrm{Ag}$ & $\mathrm{Sb}$ & As \\
\hline CKD T1 & 0.5 & 122 & 84 & 33 & 7.6 & 26 & 39 & 1.3 & 3.1 & 1.3 & 0.02 & 4.4 & 0.11 & 3 & 0.006 & 0.62 & 0.03 & 0.003 & 0.05 & 0.37 \\
\hline CKD T2 & 1 & 253 & 84 & 46 & 8.1 & 44 & 53 & 1.3 & 20 & 1.4 & 0.05 & 1.6 & 0.41 & 12 & 0.010 & 0.72 & 0.11 & 0.006 & 0.08 & 0.41 \\
\hline CKD T3 & 2 & & 77 & 46 & 7.9 & 59 & 58 & 1.0 & 25 & & 0.02 & $<0.2$ & 0.51 & 15 & 0.006 & 0.68 & 0.13 & 0.005 & 0.09 & 0.32 \\
\hline CKD T4 & 5 & 304 & 74 & 43 & 8.1 & 71 & 69 & 0.7 & 15 & $<0.5$ & 0.01 & $<0.2$ & 0.49 & 21 & $<0.005$ & 0.60 & 0.14 & 0.003 & 0.11 & 0.20 \\
\hline CKD T5 & 8 & 320 & 71 & 35 & 8.3 & 65 & 72 & 0.6 & 7.2 & $<0.5$ & 0.01 & $<0.2$ & 0.39 & 27 & $<0.005$ & 0.55 & 0.13 & 0.004 & 0.13 & 0.19 \\
\hline CKD T6 & 24 & 426 & 66 & 34 & 8.8 & 83 & 81 & 0.4 & 2.5 & $<0.5$ & 0.01 & $<0.2$ & 0.25 & 43 & 0.008 & 0.45 & 0.13 & 0.006 & 0.16 & 0.19 \\
\hline
\end{tabular}

669

670

671

672

673

674

675

676

677

678

679

680 


\section{Biographies}

682

683

684

685

686

687

688

689

690

691

692

693

694

695

696

697

698 Martina Piredda is a Ph.D. in Geoengineering and Environmental Technologies and senior

699 technician of the chemical laboratory at the Dept. of Civil-Environmental Engineering and

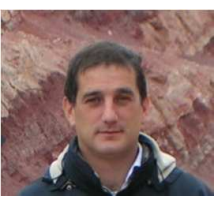

Giovanni De Giudici is a senior lecturer at the Department of Chemical and Geological Sciences, University of Cagliari (Italy). He has a thorough knowledge of mineral dissolution proceses and trace metal pollution of waters and soils. Main research activities are aimed to understand the biomineralization processes in heavy metals polluted systems.

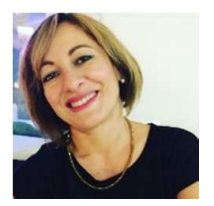


1

2

700 Architecture (University of Cagliari). Her research activity is mainly focused on accelerated 701 carbonation of alkaline residues.

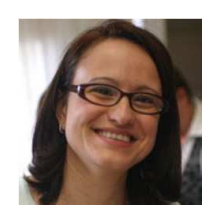

703 Simona Podda received her Ph.D. degree in electronics and informatics engineering from the 704 University of Cagliari in 2004. She is a senior researcher at CRS4 - Microscopy Laboratory 705 (Microlab) and is mainly involved in advanced electron microscopy techniques applied to 706 nanotechnologies, environmental sciences and the new materials development. 
1 Accelerated carbonation by Cement Kiln Dust in aqueous slurries:

\section{2 chemical and mineralogical investigation}

3 Daniela Medas $^{\mathrm{a},{ }^{*} \text {, Giovanna Cappai }}{ }^{\mathrm{b}}$, Giovanni De Giudici ${ }^{\mathrm{a}}$, Martina Piredda $^{\mathrm{b}}$, Simona Podda ${ }^{\mathrm{c}}$

$4{ }^{a}$ Department of Chemical and Geological Sciences, University of Cagliari, via Trentino 51, 09127, 5 Cagliari, Italy

$6{ }^{\mathrm{b}}$ DICAAR, Department of Civil and Environmental Engineering and Architecture, University of 7 Cagliari, Piazza d'Armi 1, 09123, Cagliari, Italy

$8 \quad{ }^{\mathrm{c}}$ CRS4 - Center for Advanced Studies, Research and Development in Sardinia, Parco Scientifico $9 \quad$ Polaris, Pula 09010, Italy.

11 *phone +39070 6757721 - fax +39 070 282236; e-mail: dmedas@unica.it

\section{Abstract}

14 Cement Kiln Dust accelerated carbonation in aqueous slurries at $25^{\circ} \mathrm{C}$ and 3 bar $\mathrm{PCO}_{2}$ was 15 investigated by X-ray Diffraction analysis, solution chemistry, Scanning Electron Microscopy and 16 Energy Dispersive Spectroscopy to better understand chemical and mineralogical processes 17 governing $\mathrm{CO}_{2}$ uptake. Dissolution of lime, portlandite and ettringite occurs primarily in the 18 carbonation process. These provide $\mathrm{Ca}^{2+}$ ions to react with $\mathrm{CO}_{3}{ }^{2-}$ ions leading to calcite bulk 19 precipitation from solution. Concomitantly, the dissolution of Ca-(Al)-silicate grains takes place but 20 it is limited by the formation of a Si-rich and Ca-depleted rim which appears onto the grain surfaces 21 due to an initial hydration step. The Si-rich decalcified rim hinders the diffusion of $\mathrm{Ca}^{2+}$ ions from 22 the core of silicate grains to the bulk solution. The diffusion of $\mathrm{Ca}$ ions through the rim is then the 23 rate limiting step for the carbonation of $\mathrm{Ca}-(\mathrm{Al})$-silicate, that accounts for up to $4 \%$ of the 24 carbonation potential. Achieved results elucidate the processes governing $\mathrm{CO}_{2}$ uptake by Cement 
25 Kiln Dust, and are fundamental in the perspective of enhanced $\mathrm{CO}_{2}$ sequestration by Cement Kiln 26 Dust.

\section{Keywords}

28 Accelerated carbonation, Cement Kiln Dust, $\mathrm{Ca}-(\mathrm{Al})$-silicate, $\mathrm{Ca}$ carbonate, $\mathrm{CO}_{2}$ sequestration

\section{Introduction}

Carbon dioxide $\left(\mathrm{CO}_{2}\right)$ is the most important greenhouse gas resulting from the human activity, and it is responsible for about two-thirds of the enhanced greenhouse effect. ${ }^{1}$ The development of Carbon Capture, Utilization and Storage (CCUS) technologies is one of the possible strategies for reducing $\mathrm{CO}_{2}$ in the atmosphere. Among the CCUS technologies, $\mathrm{CO}_{2}$ utilization by mineralization as carbonates is often referred as accelerated carbonation technology. ${ }^{2,3}$ Mineral carbonation is a process whereby $\mathrm{CO}_{2}$ is chemically reacted with $\mathrm{Ca}$ and/or $\mathrm{Mg}$ containing minerals to form stable carbonate materials. Carbonation can occur naturally during the weathering process of minerals, ${ }^{2}$ consisting in the reaction between natural alkaline silicates and atmospheric $\mathrm{CO}_{2}$. This process removes $\mathrm{CO}_{2}$ from the atmosphere by neutralizing the acid gas with mineral alkalinity. ${ }^{4}$ Weathering of $\mathrm{Ca}$ and $\mathrm{Mg}$ (hydr)oxides and silicates is a major consumer of excess atmospheric $\mathrm{CO}_{2}$ on a geological timescale. ${ }^{5}$ However, the kinetics of carbonation is very slow at ambient condition due to the relatively low $\mathrm{CO}_{2}$ concentration, about $0.03-0.06 \%$ by volume. ${ }^{4,6,7}$ Accelerated carbonation involves alkaline materials reacting with $\mathrm{CO}_{2}$ in controlled conditions, aiming to reduce the time required for complete carbonation and to accelerate the reaction to a timescale of a few minutes or hours, ${ }^{2,3,8}$ with the potential to capture billions of tonnes of carbon per year. ${ }^{9}$

Several up-to-date reviews on the state of the art of Mineral Carbonation (MC) technologies are available, reporting an increasing number of research projects worldwide and thus highlighting the interest and the potentiality of mineral carbonation within CCUS technologies. ${ }^{10-12}$ The undeniable benefit of mineral carbon sequestration is being the most permanent and safe method of carbon storage. However, despite the well documented advantages, the technology is not mature yet. After 
5020 years of R\&D studies since its first proposal as CCUS method, ${ }^{3}$ the state of development is still 51 at the laboratory demonstration scale and only some MC technologies have recently approached the 52 commercial scale. ${ }^{10,12}$ The main reasons for limited application on a larger scale are the low reaction 53 conversion, the slow kinetics and the energy intensity of the accelerated carbonation processes, 54 which affect the economic viability of the technology. ${ }^{10,12}$ It is well recognized that to reach the 55 highest carbonation efficiency, the major challenges are represented by the identification of the 56 controlling mechanisms and optimal operating parameters. In particular, when carbonation of 57 alkaline materials is performed through aqueous route, the following three mechanisms could be 58 involved: 1) dissolution of $\mathrm{Ca}$ and $\mathrm{Mg}$ reactive species from the solid matrix; (2) dissolution of $\mathrm{CO}_{2}$ 59 into the liquid phase and conversion of carbonic acid to bicarbonate/carbonate ions; (3) consequent 60 nucleation and precipitation of carbonates. ${ }^{2,13}$ The material particle size, the temperature, the gas 61 pressure, the liquid/solid $(\mathrm{L} / \mathrm{S})$ ratio are important parameters that could differently affect the 62 carbonation mechanisms, ${ }^{2,10}$ and a prediction on a theoretical basis of the main effects and of the 63 joint interactions between the different factors is hard to be derived. At present, the possibility to 64 enhance the reaction kinetics and the extent of the carbonation process, as well as to improve its 65 economic viability, are the focus of several accelerated carbonation experiments being conducted 66 worldwide. $^{14,15}$

67 Some of the above-mentioned drawbacks could be avoided when alkaline wastes are used as 68 feedstock instead of mineral resources. In fact, alkaline residues generally contain highly reactive $69 \mathrm{Ca}$ and $\mathrm{Mg}$ species, potentially suitable for achieving high and fast carbonate conversions without 70 the need of pre-treatment or energy intensive operating conditions. Moreover, they are available at 71 low cost near $\mathrm{CO}_{2}$ point source emissions and allow avoiding the exploitation of natural resources. 72 Finally, the resulting $\mathrm{pH}$ neutralization and mineral modification induced by carbonation could 73 improve the chemico-physical characteristics of the waste material, allowing for a safer disposal or 74 for a beneficial re-use. ${ }^{11,16,17}$ 
75 Among alkaline industrial residues that can be used as a source of carbonate-forming ions, Cement 76 Kiln Dust (CKD), a by-product from cement industry, appears interesting due to its suitable 77 composition and its availability near $\mathrm{CO}_{2}$ point source emission. The cement industry generates in 78 fact around $5 \%$ of global $\mathrm{CO}_{2}$ emissions ${ }^{17}$ and produces yearly 30 millions of tonnes of CKD. ${ }^{18}$ 79 Therefore, accelerated carbonation of $\mathrm{CKD}$ could make possible a significant reduction of the 80 cement plant $\mathrm{CO}_{2}$ emissions. $\mathrm{CKD}$ is a potential hazardous waste, in part because of the caustic 81 nature and its potential to be a skin, eye, and respiratory irritant. In addition, contaminants from the 82 raw materials and fuels tend to concentrate in CKD. ${ }^{19,20}$ Previous works on $\mathrm{CKD}^{21-23}$ mainly 83 focused on the improvement of the carbonation process by varying operating conditions such as $84 \mathrm{CO}_{2}$ pressure, temperature, liquid-to-solid (L/S) ratio, $\mathrm{CO}_{2}$ humidity, $\mathrm{CO}_{2}$ flow rate, liquid flow 85 rate, particle size, and solid pre-treatment. Gunning et al. ${ }^{16}$ studied the effects of the carbonation of 86 the CKD on the chemistry, microstructure and leaching characteristics of the solid material, 87 whereas Anderson et al. ${ }^{24}$ investigated the influence that the carbonation of CKD, performed at 88 ambient temperature and pressure, has on the mineral composition and calcite precipitation 89 mechanisms. At the current state of knowledge and in view of a scale-up of the process, further 90 laboratory scale studies are needed with the aim to better elucidate the mechanisms that may limit 91 the rate or the extent of the accelerated carbonation process on CKD.

92 In a previous work, our research group carried out accelerated carbonation experiments on CKD 93 focused on the assessment of the optimal operating condition in terms of $\mathrm{CO}_{2}$ sequestration and 94 reaction kinetics. ${ }^{25}$ The operating parameters such as $\mathrm{L} / \mathrm{S}$ ratio, $\mathrm{CO}_{2}$ pressure and temperature were 95 found to differently affect the $\mathrm{CO}_{2}$ uptake. The higher $\mathrm{CO}_{2}$ uptake and reactive species conversion 96 were attained at lower temperatures and under slurry-phase conditions. In particular, the optimal 97 water content and the optimal $\mathrm{CO}_{2}$ pressure were found to be $\mathrm{L} / \mathrm{S}=5 \mathrm{~L} / \mathrm{kg}$ and $\mathrm{PCO}_{2}=3$ bar, 98 respectively, allowing to achieve a $\mathrm{CO}_{2}$ uptake of $9.80 \%$. However, the maximum theoretical $\mathrm{CO}_{2}$ 99 sequestration capacity of $13.4 \%$ was not reached. Experimental results indicated that during 100 carbonation of $\mathrm{CKD}$ the reaction rate slows down, with an initial rapid conversion of alkaline 
101 species into carbonates and a more gradual conversion of residual un-reacted species, without

102 reaching a complete conversion.

103 In the present study, CKD was carbonated in aqueous suspension (slurry-phase carbonation) at

$10425^{\circ} \mathrm{C}$ and $\mathrm{CO}_{2}$ pressure of 3 bar to elucidate chemical and mineralogical processes limiting the $\mathrm{CO}_{2}$

105 sequestration capacity by combining X-ray Diffraction analysis (XRD), Scanning Electron

106 Microscopy (SEM), chemical analysis of solution in contact with the alkaline waste during the

107 carbonation experiment, and speciation and equilibrium calculation. Results can be useful to

108 improve understanding of the governing processes, and allow for better utilization of $\mathrm{CKD}$ in $\mathrm{CO}_{2}$

109 sequestration.

\section{2. Materials and methods}

\section{$111 \quad 2.1$ Cement Kiln Dust and carbonation experiment}

112 The CKD analysed in this study was collected from a cement plant in the South Sardinia (Italy).

113 The plant adopts a semidry process based on Lepol Grate Technology in which hot gases, coming

114 from the kiln, from an auxiliary burner and, sometimes, from the recovered hot gas of the cooler,

115 are used in two chambers for drying and pre-calcining the raw materials. A total mass sample of 60

$116 \mathrm{~kg}$ was collected at the air pollution control devices treating the exhaust gases from the kiln system

117 (electrostatic filter) and stored in airtight containers at room temperature.

118 A detailed chemical composition of CKD is reported in Table 1. Calcium is the major component

119 by far $(\mathrm{CaO}, 47 \%)$, while $\mathrm{Mg}(\mathrm{MgO}, 2.6 \%), \mathrm{Na}\left(\mathrm{Na}_{2} \mathrm{O}, 0.28 \%\right)$ and $\mathrm{K}\left(\mathrm{K}_{2} \mathrm{O}, 1.3 \%\right)$ are present in

120 small amounts. This composition is within the typical range reported in literature. ${ }^{16,22,26}$ Among the

121 potential harmful elements, $\mathrm{Pb}(463 \mathrm{mg} / \mathrm{kg}), \mathrm{V}(363 \mathrm{mg} / \mathrm{kg}), \mathrm{Zn}(177 / \mathrm{mg} / \mathrm{kg}), \mathrm{Cu}(163 \mathrm{mg} / \mathrm{kg}), \mathrm{Ni}$

122 (97 mg/kg), Mn (39 mg/kg), Tl (25 mg/kg), Cr (22 mg/kg), and As (16 mg/kg) are the most

123 abundant.

124 The operating conditions to be adopted for the accelerated carbonation experiment, in terms of 125 temperature, $\mathrm{CO}_{2}$ pressure and water content, were selected on the basis of the results obtained in a 
126 previous study by our research group (Cappai et al. ${ }^{25}$ ). The mentioned study was specifically aimed 127 at evaluating the influence on $\mathrm{CO}_{2}$ uptake and reaction kinetics exerted by the operating parameters 128 such as $\mathrm{L} / \mathrm{S}$ ratio $(0.4 ; 1 ; 3 ; 5 ; 10 \mathrm{~L} / \mathrm{kg}), \mathrm{CO}_{2}$ pressure $(1 ; 3 ; 5 ; 10$ bar) and temperature $(25 ; 50 ; 100$ $129{ }^{\circ} \mathrm{C}$ ). The highest $\mathrm{CO}_{2}$ uptake and reactive species conversion were attained at lower temperatures $130\left(25^{\circ} \mathrm{C}\right)$ and under slurry-phase conditions. In particular, the highest $\mathrm{CO}_{2}$ sequestration capacity $131(9.80 \%)$ was achieved at a $\mathrm{L} / \mathrm{S}=5$ and at operating pressure of 3 bar (please see Figure $\mathrm{S} 1$ in the 132 Supplementary Material section, reporting the $\mathrm{CO}_{2}$ uptakes over time obtained at $\mathrm{T}=25^{\circ} \mathrm{C}$ and at 133 the different pressures and L/S ratio adopted). In the present study, a quantity of $100 \mathrm{~g}$ of dry 134 sample was mixed with $500 \mathrm{~g}$ of deionized water (slurry-phase process) and exposed to a $100 \%$ $135 \mathrm{CO}_{2}$ atmosphere, at a pressure of 3 bar and a temperature of $25^{\circ} \mathrm{C}$. Test was performed in a 21 136 pressurized reactor equipped with a 1.71 internal Teflon vessel, an electric jacket for temperature 137 control, and a stirred shaft. At each set time (0.5, 1, 2, 3, 5, 8 and 24 hours), a dedicated sampling 138 device was used for drawing slurry samples, which were filtered over a $1.2 \mu \mathrm{m}$ membrane. Liquid 139 phase was used for chemical analysis (see 2.3 paragraph). Solid samples were oven dried at $40^{\circ} \mathrm{C}$

140 for 24 hours and stored in closed containers for subsequent analysis. The experiment was performed 141 in triplicate. Obtained results are perfectly in agreement and observed variations are in the range of 142 the experimental errors. For this reason and the sake of clarity, in the result and discussion 143 paragraphs, we prefer to present the mean values of chemical data, and the corresponding standard 144 deviation is indicated by error bars in reported graphics. The specific curves of each experiment are 145 reported in the Supplementary Materials (Fig. S2, S3, S4 and S5).

\section{$146 \quad 2.2$ X-ray diffraction and electron microscopy study}

147 An aliquot of $200 \mathrm{mg}$ of dried powder of untreated CKD, and solid samples collected at each set

148 time during the carbonation experiment were slightly ground in an agate mortar, and subjected to 149 XRD analysis, using conventional $\theta-2 \theta$ equipment (Panalytical) with $\mathrm{Cu} \mathrm{K} \alpha$ wavelength radiation $150(\lambda=1.54060 \AA)$, operating at $40 \mathrm{kV}$ and $40 \mathrm{~mA}$, using the $\mathrm{X}^{\prime}$ Celerator detector. 
151 SEM imaging and EDS (Energy Dispersive Spectroscopy) analysis (before and after the

152 carbonation) were carried out using a field emission (Schottky thermal field emitter) SEM, under

153 high vacuum conditions. In addition, thin sections for SEM imaging were prepared by incorporating

$154 \mathrm{CKD}$ in an epoxy resin and subsequently flattening to an appropriate thickness and polishing in

155 order to highlight the rim of the reaction. In order to obtain better quality images, samples were

156 gold coated before observation, using a SEM Coating Unit PS3 (Agar Aids for Electron

157 Microscopy).

\section{$158 \quad 2.3$ Assessment of $\mathrm{CO}_{2}$ sequestration}

159 Total carbon content analysis (LECO CHN-1000 Element Analyzer) were performed in duplicate

160 on dried solid residues obtained at the different durations. Mean values from TC (total carbon)

161 content analysis were used to estimate the $\mathrm{CO}_{2}$ uptake, with an error (difference between mean and

162 real value) always lower than $3 \%$ of the average value. The obtained mean values, expressed as

163 weight $\%$ of $\mathrm{CO}_{2}\left(\mathrm{CO}_{2}\right.$ carbonated [\%]) were used to calculate the $\mathrm{CO}_{2}$ uptake by applying the

164 equation 1 , were $\mathrm{CO}_{2 \text { initial }}[\%]$, is the TC content of the untreated $\mathrm{CKD}$, again expressed as weight \%

165 of $\mathrm{CO}_{2}$ (Equation 1).

166

167

$\mathrm{CO}_{2}$ uptake $[\%]=\frac{\mathrm{CO}_{2_{\text {carbonated }}}[\%]-\mathrm{CO}_{2 \text { initial }}[\%]}{100-\mathrm{CO}_{2} \text { carbonated }}[100$

Equation 1

168

169 The degree of sequestration in terms of reactive species conversion yields was also evaluated, by

170 comparing the amount of $\mathrm{CO}_{2}$ sequestered in each test to the maximum amount theoretically

171 possible (Equation 2). The theoretical limit of uptake was calculated based on the Steinour formula

172 (Equation 3), ${ }^{27}$ which assumes the full stoichiometric conversion to carbonates of the reactive

173 alkaline species.

174

$175 \eta \eta \%]=\frac{\mathrm{CO}_{2} \text { uptake }[\%]}{\text { ThCO }_{2} \text { uptake }[\%]} * 100$

Equation 2 
176

177

178

179

180

181

182

183

184

185

186

187

188

189

190

191

192

193

194

195

196

197

198

199

200

$$
\mathrm{ThCO}_{2} \text { uptake }\lfloor \%\rfloor=0.785\left(\mathrm{CaO}\lfloor \%\rfloor-0.56 \mathrm{CaCO}_{3}\lfloor \%\rfloor-0.7 \mathrm{SO}_{3}\lfloor \%\rfloor\right)+1.091 \mathrm{MgO}\lfloor \%\rfloor+
$$

$0.71 \mathrm{Na}_{2} \mathrm{O}[\%\rfloor+0.468\left(\mathrm{~K}_{2} \mathrm{O}\lfloor \%\rfloor-0.632 \mathrm{KCl}\lfloor \%]\right)$

Equation 3

\subsection{Chemical analysis of solutions}

The liquid phase was further filtered using a $0.45 \mu \mathrm{m}$ Millipore filtering system and $\mathrm{pH}$, redox potential, conductivity, alkalinity, trace elements and anions were evaluated on filtered aliquots. $\mathrm{pH}$ values were measured by a Ross electrode connected to a $\mathrm{pH}$-meter (Orion, Thermo Fisher Scientific, USA) after calibration against NIST buffer solutions. Redox potential was measured with a platinum electrode, and values were corrected against the Zoßell's solution. ${ }^{28}$ Conductivity was determined by conductivity meter (Thermo Orion 150 Aplus). Alkalinity was measured on filtered aliquot using both the Gran titration method with hydrochloric acid (indicator: methyl orange), and the Gran function plot method. ${ }^{29}$ Another aliquot of filtered solution was placed in acid pre-cleaned polyethylene bottles and then acidified to $1 \% \mathrm{HNO}_{3}$ for subsequent analysis by Inductively Coupled Plasma Mass Spectrometry (ICP-MS, Perkin-Elmer, Elan DRC-e, USA) and Inductively Coupled Plasma Optical Emission Spectrometry (ICP-OES, ARL Fisons ICP Analyzer 3520 B). Anions were determined by Ionic Chromatography (IC, Dionex ICS-3000) in a filtered $(0.45 \mu \mathrm{m})$ unacidified aliquot. The Detection Limit (DL) for chemical elements was calculated at 10 times the standard deviation of the blank solutions. To evaluate the accuracy and precision of trace elements determination, two reference solutions were used: the NIST SRM 1643e and the EnviroMAT Ground Water ES-L-1. Rhodium was used as an internal standard for ICP-MS analysis to correct for instrument drift. The ionic balance was always better than $\pm 10 \%$.

\subsection{Speciation and equilibrium calculations}

Speciation and equilibrium calculation were performed using the PHREEQC computer program (llnl database). Saturation indexes (SI) with respect to solid phases were calculated as SI $=\log$ $\left(\mathrm{IAP} / \mathrm{K}_{\mathrm{s}}\right)$, where IAP is the ionic activity product and $\mathrm{K}_{\mathrm{s}}$ the solubility equilibrium constant at the 
201 specific water temperature. ${ }^{30}$ pe vs $\mathrm{pH}$ diagrams were plotted using the Hydra-Medusa software and 202 its internal database complex.db and complex.elb. ${ }^{31}$

\section{3. Results}

\subsection{Mineralogical and microscopic characteristics before and after the carbonation} experiment

207 hour carbonation test. Raw $\mathrm{CKD}$ (Fig. 1a) are made up of calcite $\left(\mathrm{CaCO}_{3}\right)$, quartz $\left(\mathrm{SiO}_{2}\right)$, lime $208(\mathrm{CaO})$ and dolomite $\left(\mathrm{CaMg}\left(\mathrm{CO}_{3}\right)_{2}\right)$. In addition, peaks ascribed to cement minerals such as 209 portlandite $\left(\mathrm{Ca}(\mathrm{OH})_{2}\right)$ and ettringite $\left(\mathrm{Ca}_{6} \mathrm{Al}_{2}(\mathrm{SO} 4)_{3}(\mathrm{OH})_{12} \cdot 26 \mathrm{H}_{2} \mathrm{O}\right)$ were detected. Bixbyite $210\left(\mathrm{Mn}_{2} \mathrm{O}_{3}\right)$ and, likely, rankinite $\left(\mathrm{Ca}_{3} \mathrm{Si}_{2} \mathrm{O}_{7}\right)$ and gehlenite $\left(\mathrm{Ca}_{2} \mathrm{Al}_{2} \mathrm{SiO}_{7}\right)$ were also found. SEM 211 analysis (Fig. 2a) of the raw material shows that the grain size ranges from hundreds of nm to 212 hundreds of $\mu \mathrm{m}$, indicating high heterogeneity for the CKD. EDS spectra show that quartz (Fig. 2b), 213 calcite (Fig. 2c), and dolomite (Fig. 2d) can be easily recognized. Some micrometric crystals have a 214 hexagonal habitus typical of portlandite (images not shown).

215 XRD analysis of CKD after carbonation (Fig. 1b) reveals that the amount of calcite increases after 216 the experiment while lime, portlandite, ettringite, and bixbyite disappear. Besides the presence of 217 quartz, calcite, dolomite, and Ca-silicates (observed already in the raw sample), traces of gypsum 218 were detected after the carbonation experiment. Gypsum, most likely, derived from ettringite 219 dissolution, the subsequent release of $\mathrm{Ca}^{2+}$ and $\mathrm{SO}_{4}{ }^{2-}$ ions in solution and their precipitation as 220 gypsum and calcite.

221 To reveal grain surface processes, SEM analysis was performed on CKD sections after the 222 carbonation experiment (Fig. 3a-b). Figure 3a shows the backscattered electron image, and Figures 223 from $3 \mathrm{~b}$ to $3 \mathrm{~d}$ show the energy dispersive X-ray maps for $\mathrm{Si}$ (b), $\mathrm{Ca}(\mathrm{c})$, and $\mathrm{Al}$ (d). Micro-analysis 224 and EDS mapping indicate that these grains consist of Ca-Al-silicates, in agreement with XRD 225 analysis (see Fig. 1b) that shows residues of gehlenite in the treated sample. After the carbonation 
226 test, residual Ca-silicate grains investigated by SEM appear to be not carbonated, and enveloped by 227 a Si-rich (Fig. 3b) decalcified rim (Fig. 3c). There, Al is homogeneously distributed (Fig. 3d), and 228 elements such as Fe, S, K and V can be recognized by EDS analysis (data not shown).

\section{2 $\mathrm{CO}_{2}$ uptake}

231 Figure 4 shows the $\mathrm{CO}_{2}$ uptake and the degree of sequestration in terms of reactive species 232 conversion yields, as assessed during the accelerated carbonation test. The time-dependent curve 233 shows a very fast initial conversion of alkaline reactive species into carbonates. Then, a plateau is 234 reached, at a value lower than the maximum theoretical $\mathrm{CO}_{2}$ sequestration capacity of $13.4 \%$. As far 235 as the potential of $\mathrm{CO}_{2}$ sequestration is concerned, the results obtained in this study $(9.45 \%$ by mass 236 of $\mathrm{CO}_{2}$ ) are similar with those reported by Gunning et al. ${ }^{16}$ (9\% at ambient temperature and 2 bar 237 over $72 \mathrm{~h}$ ), but lower by ca $4 \%$ with respect to maximum sequestration potential observed for this 238 material. Understanding the mechanisms underlying this limit provide us a basis also for comparing 239 the results from different experiments.

\subsection{Chemical analysis, thermodynamic driving force and saturation state of the leached} solutions

243 XRD analysis reveals that lime, portlandite, ettringite, rankinite and gehlenite are the original 244 phases potentially involved in the carbonation process by providing cations, moving $\mathrm{pH}$ value 245 toward slightly basic conditions thus favouring the dissolution of $\mathrm{CO}_{2}$ and dissociation of carbonic 246 acid to eventually increase concentration of carbonate ion. Actually, the SI respect to the above 247 mentioned minerals are negative $(<-10)$ in the liquid phase, indicating that their dissolution is 248 favoured and, consequently, these are a source of $\mathrm{Ca}$ for the carbonation reactions.

249 Table 2 shows $\mathrm{pH}$, redox potential (Eh), electrical conductivity (Cond), and the concentration of 250 selected chemical components of the liquid phase collected during the carbonation experiment. $\mathrm{pH}$, 
251 Eh and Cond values were measured immediately after solution collection from the reactor. At the 252 same time, different aliquots were stabilized for chemical analysis. Reported values of $\mathrm{Ca}, \mathrm{Mg}$, $253 \mathrm{HCO}_{3}{ }^{-}, \mathrm{SO}_{4}{ }^{2-}, \mathrm{SiO}_{2}$ and $\mathrm{Al}$ are the total concentrations of each chemical species measured as 254 described in the paragraph 2.4. Table 3 reports PHREEQC output speciation of selected chemical 255 species (reported as ion activity) deriving from the dissolution of portlandite, ettringite, rankinite, 256 and gehlenite, and of the $\mathrm{HCO}_{3}{ }^{-}$and $\mathrm{CO}_{3}{ }^{2-}$ species involved in the precipitation of carbonate 257 minerals. Trace elements are reported in Table 4. Set times $0.5,1,2,5,8$, and 24 hours will be 258 referred to hereafter as $\mathrm{T} 1, \mathrm{~T} 2, \mathrm{~T} 3, \mathrm{~T} 4, \mathrm{~T} 5$ and $\mathrm{T} 6$, respectively. $\mathrm{pH}$ values (Table 2) are near 259 neutral and decrease from 7.55 to 6.79 , probably initially dominated by the fast dissolution of 260 portlandite and ettringite, then governed by the dissolution of $\mathrm{CO}_{2}$ in water, the formation of 261 carbonic acid and its subsequent dissociation. In addition, $\mathrm{pH}$ values $(7.11 \pm 0.07)$, observed between 262 T3 and T6 sampling, reflect the buffering effect of calcite precipitating during accelerated 263 carbonation. Redox potential values (Eh between 342 and $453 \mathrm{mV}$ ) indicate oxidizing conditions, 264 and tend to increase during the experiment.

265 Concentration of $\mathrm{Ca}$ and $\mathrm{Mg}, \mathrm{HCO}_{3}{ }^{-}$and $\mathrm{SO}_{4}{ }^{2-}$, and $\mathrm{SiO}_{2}$ and $\mathrm{Al}$ vs time in the liquid phase, 266 collected during the carbonation experiment, are shown in Fig. 5a, 5b and 5c, respectively (see also 267 Fig. S3). $\mathrm{Ca}^{2+}(60-70 \%)$ is the most abundant species (Table 3) for the total content of Ca. This 268 tends to increase in the first 2 hours, and reaches the highest concentration $(43 \mathrm{mmol} / \mathrm{l})$ at $\mathrm{T} 3$. Then, 269 it decreases from T3 to T6 $(26 \mathrm{mmol} / \mathrm{l})$. This trend is due to the release of Ca to solution because of 270 the dissolution of lime, portlandite, ettringite and $\mathrm{Ca}(\mathrm{Al})$-silicates between $\mathrm{T} 1$ and $\mathrm{T} 3$. Then, $\mathrm{Ca}$ 271 concentration decreases because of the precipitation of new phases, such as calcite and gypsum (see 272 Fig. 1 and 3.1 paragraph), or to absorption processes that become predominant over the dissolution 273 reactions between $\mathrm{T} 3$ and $\mathrm{T} 6$. In agreement, equilibrium calculation shows that calcite is 274 oversaturated in solution (Fig. 6a).

$275 \mathrm{Mg}$ concentration (Table 2, Fig. 5a and Fig. S3a) increases from T1 to T6, despite results of 276 equilibrium calculation (Fig. 6b) indicate that leached solutions are oversaturated with respect to 
$277 \mathrm{Mg}(\mathrm{Ca})$-bearing carbonate minerals such as dolomite and magnesite. In fact, although dolomite is 278 oversaturated in studied solutions (SI between 3.1 and 5), dolomite precipitation is driven by kinetic 279 factors. A high $\mathrm{Mg}^{2+} / \mathrm{Ca}^{2+}$ molar ratio (higher than $\left.5-10: 1\right)^{32}$ is required to precipitate dolomite 280 because the $\mathrm{Mg}^{2+}$ ion has a high hydration energy ${ }^{33}$. Leached solutions have a $\mathrm{Mg}^{2+} / \mathrm{Ca}^{2+}$ molar 281 ratio between 0.10 and 0.96 , and increase from T1 to T5 (Fig. 5a and Fig. S4) because of calcite 282 precipitation, reaching steady-state values between $\mathrm{T} 5\left(\mathrm{Mg}^{2+} / \mathrm{Ca}^{2+}=0.92\right)$ and $\mathrm{T} 6\left(\mathrm{Mg}^{2+} / \mathrm{Ca}^{2+}=\right.$ 283 0.96). Moreover, the kinetic of precipitation mechanism of $\mathrm{Mg}$ carbonates is controlled by the 284 supersaturation with respect to magnesite. ${ }^{34}$ In a broad range of $\mathrm{PCO}_{2}$ and $\mathrm{Mg}^{2+} / \mathrm{Ca}^{2+}$ activity ratio 285 in solution, the composition of precipitated $\mathrm{Ca}-\mathrm{Mg}$ carbonate depends only on SI respect to 286 magnesite. Under observed values ( $\mathrm{SI}<3), \mathrm{Mg}$ can be incorporated into Ca carbonate only in few 287 amount by forming low-magnesian calcite. Thus, $\mathrm{Mg}^{2+}$ ions remain in solution and do not 288 contribute to $\mathrm{CO}_{2}$ uptake during the carbonation process. Other than calcite, strontianite (Fig. 6c), 289 and witherite (Fig. 6d) are oversaturated in solution. Although XRD analysis reveals only the 290 presence of calcite, $\mathrm{Sr}$ and $\mathrm{Ba}$ carbonates could form independent phases coprecipitating with 291 calcite, but sensitivity of XRD technique does not allow their detection. Amorphous phases cannot 292 be detected by XRD as well.

293 Alkalinity $\left(\mathrm{HCO}_{3}{ }^{-}\right)$increases from T1 to T5 (Fig. 5b and Fig. S3b), and it reaches a steady-state 294 value between T5 and T6. The observed increase in alkalinity from T1 to T5 is due to the 295 continuous dissolution of $\mathrm{CO}_{2}$ into the slurry solution and relative dissociation of carbonic acid. The 296 behaviour of $\mathrm{SO}_{4}$ can be explained considering dissolution mechanism of ettringite. Ettringite is a 297 stable mineral above a $\mathrm{pH}$ of 10.7 and dissolves congruently with a $\log \mathrm{K}_{\mathrm{sp}}$ of $-111.6( \pm 0.8)$. At 298 near neutral pH, ettringite undergoes incongruent dissolution to gypsum, Al-hydroxides and Al299 hydroxy sulphates, thus controlling $\mathrm{Ca}^{2+}, \mathrm{Al}^{3+}$, and $\mathrm{SO}_{4}{ }^{2-}$ activities. ${ }^{35}$

$300 \mathrm{SiO}_{2}$ and $\mathrm{Al}$ have a similar trend (Fig. 5c and Fig S3c), showing an initial increase in concentration, 301 from $\mathrm{T} 1$ to $\mathrm{T} 2$, and a decrease until T6. Actually, $\mathrm{SiO}_{2}\left(\mathrm{SI}_{\text {quartz }}\right.$ 0.9-1.3), $\mathrm{Al}(\mathrm{OH})_{3}(\mathrm{SI} 2.0-2.8)$, and 302 Ca-Al-silicate hydrate minerals, such as gismondine $\left(\mathrm{Ca}_{2} \mathrm{Al}_{4} \mathrm{Si}_{4} \mathrm{O}_{16} \cdot 9 \mathrm{H}_{2} \mathrm{O}\right.$, SI 9-15), scolecite 
$303\left(\mathrm{CaAl}_{2} \mathrm{Si}_{3} \mathrm{O}_{10} \cdot 3 \mathrm{H}_{2} \mathrm{O}\right.$, SI 6.6-10) and laumontite $\left(\mathrm{CaAl}_{2} \mathrm{Si}_{4} \mathrm{O}_{12} \cdot 4 \mathrm{H}_{2} \mathrm{O}\right.$, SI 5.7-9.5) are oversaturated in

304 solution. Moreover, precipitation of Ca-silicate hydrate gel occurs, as observed by SEM analysis.

305 Trace elements behave according to two distinct groups: 1) V, Mo, Li, B, Ni, U and Sb show an 306 increase in concentration during the experiment; 2) $\mathrm{Rb}, \mathrm{Ba}, \mathrm{Cr}, \mathrm{Sr}, \mathrm{Zn}, \mathrm{Mn}, \mathrm{Cd}, \mathrm{Co}, \mathrm{Tl}$, and $\mathrm{As}$ are 307 released immediately in solution and then decrease during the carbonation experiment. The 308 available literature studies focusing on the influence of $\mathrm{MC}$ on trace element solubility indicate that 309 carbonation could either increase or reduce trace element mobility from alkaline residues. ${ }^{36,37}$ In 310 particular, an higher release has been observed for oxyanions, according to the fact that they are 311 often incorporated in ettringite-like minerals which dissolve upon carbonation. Other elements such 312 as heavy metals are converted into their less soluble salts or immobilized through sorption onto $313 \mathrm{CaCO}_{3}$ and/or co-precipitation into newly formed minerals.

315 4. Discussion

\section{$316 \quad 4.1$ Process chemistry and thermodynamic prediction}

317 To investigate mineralogical processes of dissolution and precipitation governing accelerated 318 carbonation of CKD, we combined chemical data with PHREEQC calculations, XRD and SEM 319 analysis. During the carbonation test, injected $\mathrm{CO}_{2}$ dissolves into solution proportionally to the $320 \mathrm{PCO}_{2}$, in accordance with Henry's law, and hydrates to carbonic acid $\left(\mathrm{H}_{2} \mathrm{CO}_{3}\right)$. Then $\mathrm{H}_{2} \mathrm{CO}_{3}$ 321 dissociates into bicarbonate $\left(\mathrm{HCO}_{3}{ }^{-}\right)$and carbonate $\left(\mathrm{CO}_{3}{ }^{2-}\right)$ ions depending on the solution $\mathrm{pH}$. 322 Simultaneously, phases such as lime and portlandite (Fig. 1a) in contact with water undergo fast 323 dissolution, in agreement with the calculated SI $(<-10)$, leading to a fast increase in $\mathrm{Ca}^{2+}$ 324 concentration from T1 to T2 (see Table 2 and Fig. 5a). As indicated by the activity values in Table $3253, \mathrm{Ca}^{2+}$ aquo ions react with $\mathrm{CO}_{3}{ }^{2-}$ leading to calcite bulk precipitation from solution.

326 Also, ettringite, ${ }^{38,39}$ rankinite and gehlenite ${ }^{2}$ take part to the carbonation process. During ettringite 327 dissolution, $\mathrm{Ca}^{2+}$ and $\mathrm{SO}_{4}{ }^{2-}$ ions are released into solution and then precipitate as gypsum and 
328 calcite. In agreement, XRD peaks of gypsum were observed in the carbonated CKD sample (Fig. $3291 \mathrm{~b})$.

330 Transformation of Ca-silicates to Ca-carbonate is characterized by a slower dissolution kinetics of 331 Ca-silicates than lime and portlandite. SEM analysis (see Fig. 3) shows that the residual non332 carbonated grains of Ca-Al-silicates are surrounded by a Si-rich decalcified rim. This can be 333 explained considering that carbonation of $\mathrm{Ca}$ silicates is accompanied by hydration ${ }^{36}$ that leads to 334 the precipitation of a Ca-silicate hydrate gel. During the carbonation process, the Ca-silicate hydrate 335 gel is progressively decalcified. ${ }^{4}$ Accordingly, the $\mathrm{Ca}^{2+} / \mathrm{SiO}_{2}{ }^{0}$ activity ratio increase in the liquid 336 phase (Fig. 7 and Fig. S3) due to the release of $\mathrm{Ca}^{2+}$ ions which become available for calcite 337 precipitation. It was demonstrated ${ }^{2,41}$ that, progressively, the Ca-silicate hydrate gel is transformed 338 into calcite and highly polymerized silicate gel. This process is the so called secondary 339 carbonation, ${ }^{36}$ but, being a slow solid state diffusion process, it has limited practical effect for 340 carbonation purposes.

341 Figures 8a and b show predominance Pourbaix diagrams for the system Ca-Al-C-Si-H-O, plotted 342 considering chemical parameters from speciation calculation for $\mathrm{T} 1$ and $\mathrm{T} 6$ samplings. 343 Predominance diagrams allow having a synoptic view of physico-chemical evolution of the 344 investigated system and prediction of mineral evolution. It is worth noting that, in Fig. 8, the $\mathrm{CaCO}_{3}$ 345 stability field increases in time from $\mathrm{T} 1$ to $\mathrm{T} 6$ indicating conditions more favourable to calcite 346 precipitation. Concomitantly, the stability field of $\mathrm{CaSiO}_{3}$ disappears in favour of the $\mathrm{Ca}_{2} \mathrm{SiO}_{4}$ field, 347 corresponding to a decrease of Si activity in solution (see Table 3) that, in turn, likely favours Si 348 storage in amorphous grain coatings. Black circles indicate $\mathrm{pH}$ and pe values of the collected liquid 349 phase at T1 (Fig. 8a) and T6 (Fig. 8b). Although black circles fall outside the calcite field, it is 350 worth nothing that chemical properties of the liquid film in contact with the alkaline solid waste 351 grains are different from that of the bulk solution. In fact, dissolution of minerals such as lime, 352 portlandite, gehlenite and rankinite leads to the consumption of hydrogen ions and, consequently, to 353 an increase in $\mathrm{pH}$ values, especially in the solution in contact with mineral grains. 


\subsection{Reaction pathways and chemical processes affecting $\mathrm{CO}_{2}$ uptake}

356 The rate and extent of carbonation of CKD is affected by transport-controlled mechanisms such as

$357 \mathrm{CO}_{2}$ and $\mathrm{Ca}^{2+}$ diffusion to/from reaction sites, boundary layer effects (diffusion across precipitate 358 coatings on particles), dissolution of $\mathrm{Ca}(\mathrm{OH})_{2}$ at the particle surface, and pore blockage or 359 precipitate coating development. ${ }^{22}$ Huntzinger et al. ${ }^{22}$ studied the extent and potential mechanisms 360 and rate behaviour of the carbonation process in CKD at ambient temperatures and pressures by 361 applying X-ray spectrometry, XRD, thermal analysis, and observed dry mass change. The major 362 reactive $\mathrm{Ca}$ species identified in $\mathrm{CKD}$ samples before carbonation experiments were lime and 363 portlandite. Authors ${ }^{22}$ stated that $\mathrm{CO}_{2}$ sequestration appears to follow unreacted core model theory. 364 As carbonation progresses, the kinetics of the reaction are attenuated by the extent of the reaction 365 due to diffusion control, with the extent of conversion never reaching completion. Anderson et 366 al. $^{24,42}$ investigated the reaction pathways ruling the carbonation processes in CKD by 367 environmental SEM, XRD, thermal gravimetric analysis/differential thermal analysis. PHREEQC 368 was used for modelling CKD reaction using a 10:1 liquid to solid ratio, and a simplified 369 composition of CKD. Authors ${ }^{24,42}$ found that lime and portlandite were the major reactants. A 370 second reaction path was the weathering of $\mathrm{Ca}$-silicates that released $\mathrm{Ca}^{2+}$ for carbonation. Three 371 types of $\mathrm{CaCO}_{3}$ precipitation mechanisms were observed: (1) diffusion of $\mathrm{CO}_{2}$ into portlandite 372 particles causing precipitation in the pores of the particle and the growth of a $\mathrm{CaCO}_{3}$ skin from the 373 outside inward, slowing vapor and aqueous diffusion by causing blockages in the pore systems, (2) 374 precipitation onto existing particles, and (3) precipitation from aqueous solution.

375 In this study, we combined XRD and SEM-EDS analysis performed before and after the 376 carbonation experiment with solution chemistry, speciation and equilibrium calculations performed 377 at each set time $(0.5,1,2,3,5,8$ and 24 hours $)$ to better investigate chemical processes limiting $378 \mathrm{CO}_{2}$ uptake. According to mineralogical and chemical investigations, we propose that the 
379 investigated accelerated carbonation of CKD follows a pathway of dissolution and precipitation 380 reactions:

381 1. hydration and/or dissolution of lime, portlandite, and ettringite and release of $\mathrm{Ca}^{2+}$ ions in 382

4. dissociation of bicarbonate ions into carbonate ions in the solution in contact with the alkaline solid waste:

3. contemporary dissolution of gaseous $\mathrm{CO}_{2}$ into solution and formation of bicarbonate ions according to the observed $\mathrm{pH}$ values $(7.2 \pm 0.2)$ :

$\mathrm{CO}_{2}+\mathrm{H}_{2} \mathrm{O} \leftrightarrow \mathrm{H}^{+}+\mathrm{HCO}_{3}^{-}$

$$
\mathrm{HCO}_{3-}-\leftrightarrow \mathrm{H}^{+}+\mathrm{CO}_{3}{ }^{2-}
$$

5. calcite precipitation from solution:

$$
\mathrm{Ca}^{2+}+\mathrm{CO}_{3}^{2-} \leftrightarrow \mathrm{CaCO}_{3}
$$

In a first stage, a rapid transformation of lime, portlandite and ettringite into Ca-carbonate takes place. After their consumption, $\mathrm{Ca}$ from the $\mathrm{Ca}-(\mathrm{Al})$-silicate phases diffuses toward the surface of the grains, and $\mathrm{Ca}^{2+}$ ions are dissolved into solution and precipitated as calcite. Leaching of $\mathrm{Ca}$ from $\mathrm{Ca}-(\mathrm{Al})$-silicates results in a withdrawing $\mathrm{Ca}-(\mathrm{Al})$-silicate core covered by a Si-rich decalcified rim (see Fig. 3) that may change the rate and mechanism of dissolution. During decalcification of the external rim, $\mathrm{Ca}^{2+}$ ions are dissolved into solution, while Si remains in the solid state, hindering the 
405 diffusion of $\mathrm{Ca}^{2+}$ ions from the grain core, and limiting conversion. ${ }^{20,41}$ Indeed, XRD analysis (see 406 Fig. 1b) show that $\mathrm{Ca}$ silicate grains are still present in carbonated $\mathrm{CKD}$, because formation of the 407 external rim results in diffusion to be the rate limiting step, then limiting the carbonation process. 408 This is reflected in the time-dependent curve of $\mathrm{CO}_{2}$ uptake in Fig. 4 that shows an exponential 409 shape, suggesting an initial rapid conversion of $\mathrm{Ca}$ reactive species into carbonates, and a 410 subsequent decrease in reaction rate without reaching a complete conversion as estimated by the 411 maximum theoretical $\mathrm{CO}_{2}$ sequestration capacity (13.4\%). This behaviour indicates that carbonation 412 process follows an "unreacted core model". 22,40 Moreover, in our slurries experiments the rim is not 413 made of calcite, as observed by Anderson ${ }^{42}$, the latter mineral precipitating from bulk solution. 414 Thus, we argued that the rim hindering the unreacted core appears to be dependent on the 415 experimental condition. Specifically, the composition of the rim could depend on the composition 416 of the given CKD and also on the liquid-solid ratio. Moreover, CKD material comprise several 417 minerals whose relative abundance is not constant. These findings allow us to assert that a potential 418 optimization of the $\mathrm{CO}_{2}$ uptake by $\mathrm{CKD}$ could be achieved properly selecting specific additives ${ }^{43}$ to 419 hinder the formation of external layers for improving diffusion of $\mathrm{Ca}$ ions through the Ca-Al-silicate 420 grains to enhance carbonation reaction of the unreacted particle core.

\section{5. Conclusions}

422 The carbonation of $\mathrm{CKD}$ has been proved to be an effective technology to capture $\mathrm{CO}_{2}$, and it need 423 to be improved for being applied at a commercial scale. To reach the highest sequestration capacity, 424 the main goals are represented by the identification of the optimal operating parameters and the 425 limiting reaction mechanisms. In order to achieve a better understanding of the chemical and 426 mineralogical processes affecting carbonation and $\mathrm{CO}_{2}$ uptake efficiency of $\mathrm{CKD}$, a slurry-phase 427 accelerated carbonation was performed at $25^{\circ} \mathrm{C}$ and 3 bar. The $\mathrm{CO}_{2}$ uptake by $\mathrm{CKD}$ follows an 428 exponential increase, achieving a carbonation capacity of $9.45 \%$ in the first hour. XRD analysis 429 indicates that the reactive species in CKD are lime, portlandite, ettringite, rankinite, and gehlenite. 
430 Direct observations by XRD and SEM, and geochemical modelling of solution in contact with CKD 431 during the carbonation experiment indicate that $\mathrm{CO}_{2}$ uptake is limited by the formation of a $\mathrm{Si}$-rich 432 decalcified layer covering the residual Ca-Al-silicates grains. In fact, in the presence of the Si-rich 433 decalcified layer, the solution chemistry reached a stationary state and carbonation ceased before 434 reaching the maximum theoretical uptake (13.4\%). Literature studies on CKD observed the 435 formation of a rim made of calcite instead of a Si-rich decalcified layer. Thus, we argued that the 436 knowledge of the specific mechanism active in a given CKD carbonation set-up (reactor and 437 materials) has direct implication for the scaling up to pilot or pre-industrial scale experiment. The 438 findings from the present study indicate that a further process optimization is possible, aimed at 439 avoiding the formation of Si-rich decalcified layer. On the basis of the $\mathrm{CO}_{2}$ sequestration capacity 440 of $9.45 \%$ assessed during the present study, since 0.2 tons of CKD for every ton of clinker are 441 produced $^{17}$ and 0.507 tons of $\mathrm{CO}_{2} /$ ton of clinker are emitted, ${ }^{44}$ the carbonation treatment would 442 have the potential for sequestering $3.7 \%$ of the cement plant $\mathrm{CO}_{2}$ emissions, which would increase 443 to up to $5.27 \%$ if the maximum theoretical $\mathrm{CO}_{2}$ sequestration capacity of $13.4 \%$ is exploited. This 444 increase of carbonation efficiency is a crucial aspect in lowering the industrial capture cost, which is 445 still considered too high for the implementation of MC on a large scale. Further studies with slurry 446 accelerated carbonation of $\mathrm{CKD}$ would be useful in order to define the optimal conditions for 447 enhanced carbonation process also by using additives to hinder silica rim formation.

\section{Acknowledgements}

450 This work was funded by RAS grant CRP 25 659. The authors acknowledge two anonymous 451 reviewers greatly for their useful comments, and the Managing Editor, Sarah Watson, for the 452 manuscript handling. 


\section{References}

455 1. Nyambura MG, Mugera GW, Felicia, PL and Gathura NP. Carbonation of Brine Impacted 456 Fractionated Coal Fly Ash: Implications for $\mathrm{CO}_{2}$ Sequestration. $J$ Environ Manage 92(3): $457 \quad 655-664(2011)$.

458 2. Pan SY, Chang EE and Chiang PC. $\mathrm{CO}_{2}$ capture by accelerated carbonation of alkaline 459 wastes: A review on its principles and applications. Aerosol Air Qual Re. 12: 770-791 $460 \quad$ (2012).

461 3. Seifritz W. $\mathrm{CO}_{2}$ Disposal by Means of Silicates. Nature 345 (6275): 486-486 (1990).

462 4. Lackner KS. Carbonate chemistry for sequestering fossil carbon. Annu Rev Energy Environ $463 \quad$ 27: 193-232 (2002).

464 5. Rau G. $\mathrm{CO}_{2}$ Mitigation via Capture and Chemical Conversion in Seawater. Environ Sci 465 Technol 45(3): 1088-1092 (2011).

466 6. Galan I, Andrade $\mathrm{C}$ and Castellote $\mathrm{M}$. Natural and accelerated $\mathrm{CO}_{2}$ binding kinetics in 467 cement paste at different relative humidities. Cem Concr Res 49: 21-28 (2013).

468 7. Muduli SD, Nayak BD, Dhal NK and Mishra BK. Atmospheric $\mathrm{CO}_{2}$ Sequestration through 469 Mineral Carbonation of Fly Ash. Greener Journal of Physical Sciences 4: 273-278 (2014).

470 8. Lim M, Han GC, Ahn JW and You KS. Environmental Remediation and Conversion of 471 Carbon Dioxide $\left(\mathrm{CO}_{2}\right)$ into Useful Green Products by Accelerated Carbonation Technology. 472 Int J Environ Res, Public Health 7(1): 203-228 (2010).

473 9. Renforth P, Washbourne CL, Taylder J and Manning DAC. Silicate Production and 474 Availability for Mineral Carbonation. Environ Sci Technol 45(6): 2035-2041(2011).

475 10. Sanna A, Uibu, M, Caramanna, G, Kuusik, R and Maroto-Valer, MM. A Review of Mineral 476 Carbonation Technologies to Sequester $\mathrm{CO}_{2}$. Chem Soc Rev 43: 8049-8080 (2014).

477 11. Pan SY, Chiang A, Chang EE, Lin YP, Kim H and Chiang PC. An innovative approach to 478 integrated carbon mineralization and waste utilization: a review. Aerosol Air Qual Res 15: 479 1072-1091(2015). 
480 12. Zevenhoven R, Fagerlund J and Songok JK. $\mathrm{CO}_{2}$ mineral sequestration: developments 481 toward large scale application. Greenhouse Gases Sci Technol 1: 48-57 (2011).

482 13. Huijgen WJJ, Witkamp GJ and Comans RNJ. Mineral $\mathrm{CO}_{2}$ sequestration by steel slag 483 carbonation. Environ Sci Technol 39 (24): 9676-9682 (2005).

484 14. Ukwattage NL, Ranjith PG, Yellishetty M, Bui HH and Xu T. A laboratory-scale study of 485 the aqueous mineral carbonation of coal fly ash for $\mathrm{CO}_{2}$ sequestration. J Clean Prod 103: $486 \quad 665-674(2015)$.

487 15. Azdarpour A, Asadullah M, Mohammadian E, Hamidi H, Junin R and Karaei MA. A review 488 on carbon dioxide mineral carbonation through $\mathrm{pH}$-swing process. Chem Eng J, 279: 615$489630(2015)$.

490 16. Gunning PJ, Hills CD and Carey PJ. Accelerated carbonation treatment of industrial wastes. $491 \quad$ Waste Manage 30(6): 1081-1090 (2010).

492 17. Bobicki ER, Liu Q, Xu Z and Zeng H. Carbon capture and storage using alkaline industrial $493 \quad$ wastes. Prog. Energy Combust Sci 38(2): 302-320 (2012).

494 18. Sreekrishnavilasam A, King S and Santagata M. Characterization of fresh and landfilled 495 cement kiln dust for reuse in construction applications. Eng Geol 85(1-2): 165-173 (2006).

496 19. Van Oss HG and Padovani AC. Cement manufacture and the environment, Part II: 497 environmental challenges and opportunities. J Ind Ecol 7(1): 93-127 (2003).

498 20. Olajire AA. A review of mineral carbonation technology in sequestration of $\mathrm{CO}_{2} . J$ Petrol $499 \quad$ Sci Eng 109: 364-392 (2013).

500 21. Huntzinger DN, Gierke JS, Sutter LL, Kawatra SK and Eisele TC. Mineral carbonation for 501 carbon sequestration in cement kiln dust from waste piles. J Hazard Mater 168(1): 31-37 $502 \quad$ (2009).

503 22. Huntzinger DN, Gierke JS, Kawatra SK, Eisele TC and Sutter LL. Carbon Dioxide 504 Sequestration in Cement Kiln Dust through Mineral Carbonation. Environ Sci Technol 505 43(6): 1986-1992 (2009). 
506 23. Ramme BW, Naik TR and Kraus RN. An Investigation of $\mathrm{CO}_{2}$ Sequestration Through 507 Mineralization. 2nd International Conference on Sustainable Construction Materials and 508 Technologies, Ancona, Italy, 28 - 30 June (2010).

509 24. Anderson CP, Sutter LL, Huntzinger DN and Gierke JS. Effects of carbonation on the 510 mineral composition of cement kiln dust. In International Cement Microscopy Association 51129 th International Conference on Cement Microscopy, 441-470 (2007).

512 25. Cappai G, Carucci A, De Giudici G, Medas D, Muntoni A, Orru G and Piredda M. Carbon 513 dioxide sequestration by accelerated carbonation of cement kiln dust (CKD). Sardinia 2013, 514 14th International Waste Management and Landfill Symposium., S. Margherita di Pula 515 (CA), Italy, 30th September-4th October (2013).

516 26. Ali MAM and Yang HS. Utilization of Cement Kiln Dust in industry Cement Bricks. 517 Geosystem Eng 14(1): 29-34 (2011).

518 27. Steinour HH. Some Effects of Carbon Dioxide on Mortars and Concrete - A Discussion. J. 519 Am. Concr. Inst., 55(2): 905-907 (1959).

520 28. Nordstrom DK. Thermochemical redox equilibria of ZoBell's solution. Geochim 521 Cosmochim Acta 41(12): 1835-1841 (1977).

522 29. Gran G. Determination of the equivalence 681 point in potentiometric titrations. Acta Chem $523 \quad$ Scand 4: 559-577 (1950).

524 30. Parkhurst DL and Appelo CAJ. User's guide to PHREEQC (version 2) - A computer 525 program for speciation, batch-reaction, one-dimensional transport, and inverse geochemical 526 calculations. U.S. Geol. Surv. Water-Resour. Invest. Rep. 99-4259 (1999).

527 31. Puigdomènech I. HYDRA-MEDUSA (Make Equilibrium Diagrams Using Sophisticated 528 Algorithms). Windows interface to the MS-DOS versions of INPUT, SED and PREDOM 529 (FORTRAN programs drawing chemical equilibrium diagrams) Vers. 6 December 2010. $530 \quad$ Royal Institute of Technology (KTH), Stockholm. 
531 32. Folk R and Land L. Mg/Ca ratio and salinity: two controls over crystallization of dolomite. 532 Am Assoc Pet Geol Bull 59: 60-68 (1975).

533 33. Xu J, Yan C, Zhang F, Konishi H, Xu H and Tenga HH. Testing the cation-hydration effect 534 on the crystallization of Ca-Mg-CO3 systems. Proc Natl Acad Sci U S A. 110(44):17750-5 $535 \quad$ (2013).

536 34. Prigiobbe V, Hänchen M, Werner M, Baciocchi R, and Mazzotti M. Mineral carbonation 537 process for $\mathrm{CO}_{2}$ sequestration, $9^{\text {th }}$ International Conference on Greenhouse Gas Control $538 \quad$ Technologies, Energy Procedia 1, 4885-4890(2009)

539 35. Mynenia SCB, Trainaa SJ, and Logana TJ. Ettringite solubility and geochemistry of the $540 \mathrm{Ca}(\mathrm{OH})_{2}-\mathrm{Al}_{2}\left(\mathrm{SO}_{4}\right)_{3}-\mathrm{H}_{2} \mathrm{O}$ system at 1 atm pressure and $298 \mathrm{~K}$. Chem Geol 148(1-2):1-19 $541 \quad$ (1998).

542 36. Bertos MF, Simons SJR, Hills CD and Carey PJ. A review of accelerated carbonation 543 technology in the treatment of cement-based materials and sequestration of $\mathrm{CO}_{2} . J$ Hazard $544 \quad$ Mater 112(3): 193-205 (2004).

545 37. Cappai G, Cara S, Muntoni A, Piredda M. Application of accelerated carbonation on MSW 546 combustion APC residues for metal immobilization and $\mathrm{CO}_{2}$ sequestration. J Hazard Mater, 547 207-208: 159-164 (2012).

548 38. Nishikawa T, Suzuki K, Ito S, Sato K and Takebe T. Decomposition of synthesized 549 ettringite by carbonation. Cem Concr Res 22(1): 6-14 (1992).

550 39. Lange LC, Hills $\mathrm{CD}$ and Poole AB. Preliminary investigation into the effects of 551 carbonations on cement — solidified hazardous wastes. Environ Sci Technol 30(1): 5-30 $552 \quad(1996)$

553 40. Huijgen WJJ and Comans RNJ. Mineral $\mathrm{CO}_{2}$ sequestration by carbonation of industrial 554 residues. Literature review and selection of residue ECN-C-05-074 (2005). 
555 41. Thiery M, Villain G, Dangla P and Platret G. Investigation of the Carbonation front Shape 556 on Cementitious Materials: Effects of the Chemical Kinetics. Cem Concr Res 37(7): 1047$557 \quad 1058(2007)$.

558 42. Anderson CP. Effects of carbonation on the mineral composition of cement kiln dust, 559 Master's Thesis, Michigan Technological University (2006).

560 43. Bonfils B, Bourgeois F, Julcour-Lebigue C, Guyot F and Chiquet P. Understanding the 561 Chemistry of Direct Aqueous Carbonation with Additives Through Geochemical Modelling. 562 Energy Procedia, 10th International Conference on Greenhouse Gas Control Technologies, 563 2011, vol. 4. pp. 3809-3816.

564 44. IPCC - Intergovernmental Panel on Climate Change. Revised 1996 IPCC Guidelines for 565 National Greenhouse Gas Inventories. Reference Manual (Revised). Vol 3. J.T. Houghton et 566 al., IPCC/OECD/IEA, Paris, France (1997). 
1

2

3

585

586

587

588

589

590

591

592

593

594

595

596

597

598

599

600

601

602

603

604

605

606

607

608

609

610

611

612

613

614 Figure 7. Mean $\mathrm{Ca}^{2+} / \mathrm{SiO}_{2}{ }^{0}$ activity ratio concentration vs time in the liquid phase. grain. carbonation test. molar ratio is shown.

Figure 1. XRD pattern of CKD before (a) and after the carbonation test (b). Cal (calcite), Qz (quarz), Lime (lime), Dol (dolomite), Prt (portlandite), Ettr (ettringite), Bix (bixbyite), Rank (rankinite), Gh (gehlenite), Gyps (gypsum).

Figure 2. Scanning Electron Microscopy analysis of raw CKD. a) Overview of the CKD sample grain size; b) image and microanalysis of a quartz grain; c) image and microanalysis of a calcite grain; d) image and microanalysis of a dolomite

Figure 3. Scanning Electron Microscopy analysis of a CKD section after the carbonation experiment (T6). Backscattered electron image (a) and the results of $\mathrm{Si}(\mathrm{b})$, $\mathrm{Ca}(\mathrm{c})$, and $\mathrm{Al}$ (d) mapping by energy dispersive X-ray on the CKD sample. Arrows indicate the Si-rich decalcified rim that envelops the residual non-carbonated grains of Ca-Al-silicates.

Figure 4. $\mathrm{CO}_{2}$ uptake and degree of sequestration in terms of reactive species conversion yields during the accelerated

Figure 5. Mean concentration of $\mathrm{Ca}, \mathrm{Mg}(\mathrm{a}), \mathrm{HCO}_{3}, \mathrm{SO}_{4}(\mathrm{~b}), \mathrm{SiO}_{2}$ and $\mathrm{Al}(\mathrm{c})$ vs time in the liquid phase. $\mathrm{Also}^{\mathrm{M}} \mathrm{Mg}^{2+} / \mathrm{Ca}^{2+}$

615 
616 Figure 8. pe vs pH diagrams for the system Ca-Al-C-Si-H-O for liquid phase collected at T1 (a) and T6 (b). Diagrams are 617 drawn by the chemical equilibrium-diagram-tool Hydra/Medusa. Black circles indicate pH and pe values of the collected 618 liquid phase at $\mathrm{T} 1$ (a) and $\mathrm{T6}(\mathrm{b})$. Concentrations for $\mathrm{Ca}^{2+}-\mathrm{Al}^{3+}-\mathrm{CO}_{3}{ }^{2-}-\mathrm{H}_{4} \mathrm{SiO}_{4}{ }^{0}$ come from speciation calculation performed 619 by PHREEQC.

620

621

622

623

624 Table 1. Elemental composition of the CKD (from Cappai et al. ${ }^{25}$ )

\begin{tabular}{|c|c|c|c|}
\hline Element & $(\%)$ & Element & $(\mathrm{mg} / \mathrm{kg})$ \\
\hline $\mathrm{Al}_{2} \mathrm{O}_{3}$ & $2.95 \pm 0.05$ & As & $16.12 \pm 0.79$ \\
\hline $\mathrm{CaO}$ & $46.75 \pm 0.91$ & $\mathrm{Ba}$ & $185 \pm 9$ \\
\hline $\mathrm{Fe}_{2} \mathrm{O}_{3}$ & $1.94 \pm 0.05$ & $\mathrm{Cd}$ & $7.08 \pm 1.22$ \\
\hline $\mathrm{K}_{2} \mathrm{O}$ & $1.30 \pm 0.01$ & $\mathrm{Co}$ & $5.66 \pm 0.89$ \\
\hline $\mathrm{MgO}$ & $2.64 \pm 0.08$ & $\mathrm{Cr}$ & $22.12 \pm 1.34$ \\
\hline $\mathrm{MnO}$ & $0.05 \pm 0.00$ & $\mathrm{Cu}$ & $163 \pm 9$ \\
\hline $\mathrm{Na}_{2} \mathrm{O}$ & $0.28 \pm 0.10$ & Mo & $38.87 \pm 3.13$ \\
\hline $\mathrm{P}_{2} \mathrm{O}_{5}$ & N.D. & $\mathrm{Ni}$ & $97.02 \pm 9.59$ \\
\hline $\mathrm{SiO}_{2}$ & $18.65 \pm 0.21$ & $\mathrm{~Pb}$ & $463 \pm 28.0$ \\
\hline $\mathrm{TiO}_{2}$ & $0.12 \pm 0.01$ & $\mathrm{Sb}$ & $6.82 \pm 1.13$ \\
\hline \multirow[t]{2}{*}{ LOI } & $26.80 \pm 0.10$ & $\mathrm{Se}$ & $13.31 \pm 0.10$ \\
\hline & & $\mathrm{Tl}$ & $24.87 \pm 1.10$ \\
\hline Soluble anions & $(\mathrm{mg} / \mathrm{kg})$ & $\mathrm{V}$ & $363 \pm 7$ \\
\hline Cloride & $3204 \pm 93$ & $\mathrm{Zn}$ & $177 \pm 10$ \\
\hline
\end{tabular}

625

Sulphate $7382 \pm 370$

626

627

628

629

630

631 
1

2

3

4

5

6

7

8

9

10

11

12

13

14

15

16

17

18

19

20

21

22

23

24

25

26

27

28

29

30

31

32

33

34

35

36

37

38

39

40

41

42

43

44

45

46

47

48

49

50

51

52

53

54

55

56

57

58

59

60
632

633

634

635

636

637 Table 2. Mean values of $\mathbf{p H}$, redox potential (Eh), electrical conductivity (Cond), and mean concentration of selected chemical 638 components of the liquid phase collected during the carbonation experiments.

\begin{tabular}{|c|c|c|c|c|c|c|c|c|c|c|}
\hline Sample & $\begin{array}{l}\text { Time } \\
\text { (hour) }\end{array}$ & pH & $\begin{array}{c}\mathbf{E h} \\
(\mathrm{mV})\end{array}$ & $\begin{array}{c}\text { Cond } \\
(\mathrm{mS} / \mathrm{cm})\end{array}$ & Ca & Mg & $\begin{array}{l}\mathrm{HCO}_{3} \\
(\mathrm{mmol} / \mathrm{l})\end{array}$ & $\mathrm{SO}_{4}$ & $\mathrm{SiO}_{2}$ & $\begin{array}{c}\mathbf{A l} \\
(\mu \mathrm{mol} / \mathrm{l})\end{array}$ \\
\hline CKD T1 & 0.5 & 7.55 & 342 & 6.8 & 22 & 3 & 14 & 31 & 3.8 & 23 \\
\hline CKD T2 & 1 & 6.79 & 374 & 7.7 & 40 & 11 & 60 & 34 & 4.5 & 30 \\
\hline CKD T3 & 2 & 7.18 & 369 & 9.1 & 43 & 19 & 81 & 34 & 3.7 & 16 \\
\hline CKD T4 & 5 & 7.04 & 425 & 9 & 37 & 26 & 93 & 29 & 2.4 & 5 \\
\hline CKD T5 & 8 & 7.05 & 451 & 8 & 28 & 30 & 103 & 23 & 2 & 4 \\
\hline CKD T6 & 24 & 7.18 & 453 & 10.3 & 26 & 36 & 106 & 25 & 1.6 & 2 \\
\hline
\end{tabular}

639

640

641

642

643

644

645

646

647

648

649

650

651

652

https://mc.manuscriptcentral.com/ghg-wiley 
659 Table 3. Mean activity of $\mathrm{Ca}^{2+}, \mathrm{HCO}_{3}{ }^{-}, \mathrm{CO}_{3}{ }^{2-}, \mathrm{SiO}_{2}{ }^{0}, \mathrm{SO}_{4}{ }^{2-}$ and $\mathrm{Al}^{3+}$ in the liquid phase collected during the carbonation 660 experiment calculated by PHREEQC.

661

662

663

664

665

666

667

668

669

670

671

672

673

674

675

676

677

678

679

\begin{tabular}{|c|c|c|c|c|c|c|c|}
\hline Sample & $\begin{array}{l}\text { Time } \\
\text { (hour) }\end{array}$ & $\mathrm{Ca}^{2+}$ & $\mathrm{HCO}_{3}^{-}$ & $\begin{array}{r}\mathrm{CO}_{3}{ }^{2-} \\
(\mathrm{m}\end{array}$ & $\begin{array}{l}\mathrm{SiO}_{2}{ }^{0} \\
1 / 1)\end{array}$ & $\mathrm{SO}_{4}^{-2}$ & $\mathbf{A l}^{3+}$ \\
\hline CKD T1 & 0.5 & $5.66 \mathrm{E}-03$ & $9.20 \mathrm{E}-03$ & $1.40 \mathrm{E}-05$ & $1.78 \mathrm{E}-03$ & $7.50 \mathrm{E}-03$ & $8.30 \mathrm{E}-13$ \\
\hline CKD T2 & 1 & $9.10 \mathrm{E}-03$ & $3.90 \mathrm{E}-02$ & $1.10 \mathrm{E}-05$ & $2.12 \mathrm{E}-03$ & $6.20 \mathrm{E}-03$ & $1.00 \mathrm{E}-10$ \\
\hline CKD T3 & 2 & $9.48 \mathrm{E}-03$ & $5.00 \mathrm{E}-02$ & $3.40 \mathrm{E}-05$ & $1.77 \mathrm{E}-03$ & $5.50 \mathrm{E}-03$ & $9.70 \mathrm{E}-12$ \\
\hline CKD T4 & 5 & $8.11 \mathrm{E}-03$ & $5.80 \mathrm{E}-02$ & $2.80 \mathrm{E}-05$ & $1.14 \mathrm{E}-03$ & $4.60 \mathrm{E}-03$ & $1.60 \mathrm{E}-11$ \\
\hline CKD T5 & 8 & $6.22 \mathrm{E}-03$ & $6.50 \mathrm{E}-02$ & $3.20 \mathrm{E}-05$ & $9.59 \mathrm{E}-04$ & $3.70 \mathrm{E}-03$ & $1.20 \mathrm{E}-11$ \\
\hline CKD T6 & 24 & $5.66 \mathrm{E}-03$ & $6.60 \mathrm{E}-02$ & $4.40 \mathrm{E}-05$ & 7.39E-04 & $3.90 \mathrm{E}-03$ & $1.80 \mathrm{E}-12$ \\
\hline
\end{tabular}


1

2

3

4

5

6

7

8

9

10

11

12

13

14

15

16

17

18

19

20

21

22

23

24

25

26

27

28

29

30

31

32

33

34

35

36

37

38

39

40

41

42

43

44

45

46

47

48

49

50

51

52

53

54

55

56

57

58

59

60
680

681

682

683

684

685

686

687

688 Table 4. Mean concentration of trace elements of the liquid phase collected during the carbonation experiment.

\begin{tabular}{|c|c|c|c|c|c|c|c|c|c|c|c|c|c|c|c|c|c|c|c|c|}
\hline Sample & $\begin{array}{l}\text { Time } \\
\text { (hour) }\end{array}$ & V & $\mathrm{Rb}$ & $\mathrm{Sr}$ & Mo & B & $\mathrm{Li}$ & $\mathrm{Ba}$ & $\mathrm{Mn}$ & $\mathrm{Zn}$ & $\mathrm{Cd}$ & $\begin{array}{c}\mathrm{Cr} \\
(\mu \mathrm{mol}\end{array}$ & $\mathrm{Co}$ & $\mathrm{Ni}$ & $\mathrm{Pb}$ & $\mathrm{Tl}$ & $\mathrm{U}$ & $\mathrm{Ag}$ & $\mathrm{Sb}$ & As \\
\hline CKD T1 & 0.5 & 122 & 84 & 33 & 7.6 & 26 & 39 & 1.3 & 3.1 & 1.3 & 0.02 & 4.4 & 0.11 & 3 & 0.006 & 0.62 & 0.03 & 0.003 & 0.05 & 0.37 \\
\hline CKD T2 & 1 & 253 & 84 & 46 & 8.1 & 44 & 53 & 1.3 & 20 & 1.4 & 0.05 & 1.6 & 0.41 & 12 & 0.010 & 0.72 & 0.11 & 0.006 & 0.08 & 0.41 \\
\hline CKD T3 & 2 & 273 & 77 & 46 & 7.9 & 59 & 58 & 1.0 & 25 & 0.7 & 0.02 & $<0.2$ & 0.51 & 15 & 0.006 & 0.68 & 0.13 & 0.005 & 0.09 & 0.32 \\
\hline CKD T4 & 5 & 304 & 74 & 43 & 8.1 & 71 & 69 & 0.7 & 15 & $<0.5$ & 0.01 & $<0.2$ & 0.49 & 21 & $<0.005$ & 0.60 & 0.14 & 0.003 & 0.11 & 0.20 \\
\hline CKD T5 & 8 & 320 & 71 & 35 & 8.3 & 65 & 72 & 0.6 & 7.2 & $<0.5$ & 0.01 & $<0.2$ & 0.39 & 27 & $<0.005$ & 0.55 & 0.13 & 0.004 & 0.13 & 0.19 \\
\hline CKD T6 & 24 & 426 & 66 & 34 & 8.8 & 83 & 81 & 0.4 & 2.5 & $<0.5$ & 0.01 & $<0.2$ & 0.25 & 43 & 0.008 & 0.45 & 0.13 & 0.006 & 0.16 & 0.19 \\
\hline
\end{tabular}

689

690 
691

692

693

694

695

696

697

698

699

700

701

702 Biographies

703

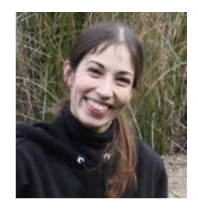

704 Daniela Medas is a research assistant at the Department of Chemical and Geological Sciences,

705 University of Cagliari (Italy). She has a thorough knowledge of trace metal pollution of waters and

706 soils. Main research activities are aimed to understand the geo-bio interactions in polluted and not

707 polluted soils and waters.

708

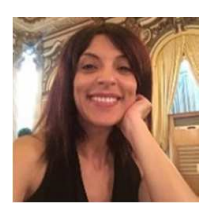


709 Giovanna Cappai is Associate Professor in Sanitary-Environmental Engineering at the Dept. of 710 Civil-Environmental Engineering and Architecture of the University of Cagliari. Her current 711 research activity mainly concerns accelerated carbonation of alkaline residues and remediation of 712 contaminated sites.

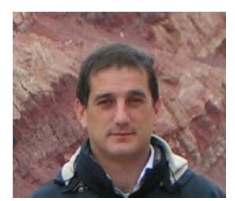

714 Giovanni De Giudici is a senior lecturer at the Department of Chemical and Geological Sciences, 715 University of Cagliari (Italy). He has a thorough knowledge of mineral dissolution proceses and 716 trace metal pollution of waters and soils. Main research activities are aimed to understand the 717 biomineralization processes in heavy metals polluted systems.

718

719

720

721

722

723

724

725

726

727

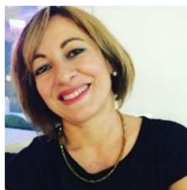

Martina Piredda is a Ph.D. in Geoengineering and Environmental Technologies and senior technician of the chemical laboratory at the Dept. of Civil-Environmental Engineering and Architecture (University of Cagliari). Her research activity is mainly focused on accelerated carbonation of alkaline residues.

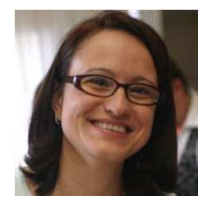

Simona Podda received her Ph.D. degree in electronics and informatics engineering from the University of Cagliari in 2004. She is a senior researcher at CRS4 - Microscopy Laboratory (Microlab) and is mainly involved in advanced electron microscopy techniques applied to nanotechnologies, environmental sciences and the new materials development. 
XRD pattern of CKD before (a) and after the carbonation test (b). Cal (calcite), Qz (quarz), Lime (lime), Dol (dolomite), Prt (portlandite), Ettr (ettringite), Bix (bixbyite), Rank (rankinite), Gh (gehlenite), Gyps (gypsum).

$41 \times 21 \mathrm{~mm}(300 \times 300$ DPI $)$ 

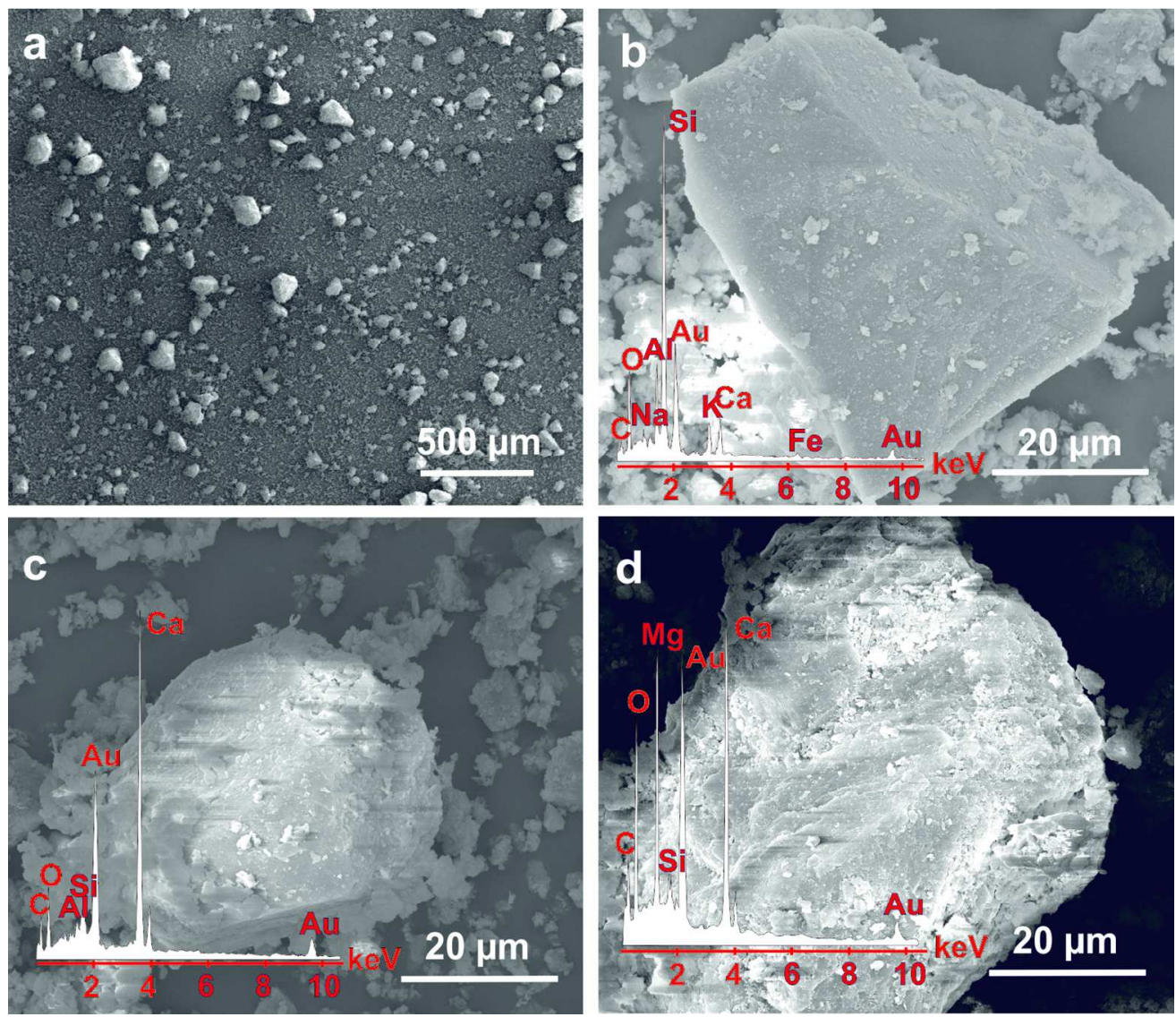

Scanning Electron Microscopy analysis of raw CKD. a) Overview of the CKD sample grain size; b) image and microanalysis of a quartz grain; c) image and microanalysis of a calcite grain; d) image and microanalysis of a dolomite grain.

$134 \times 116 \mathrm{~mm}(300 \times 300 \mathrm{DPI})$ 

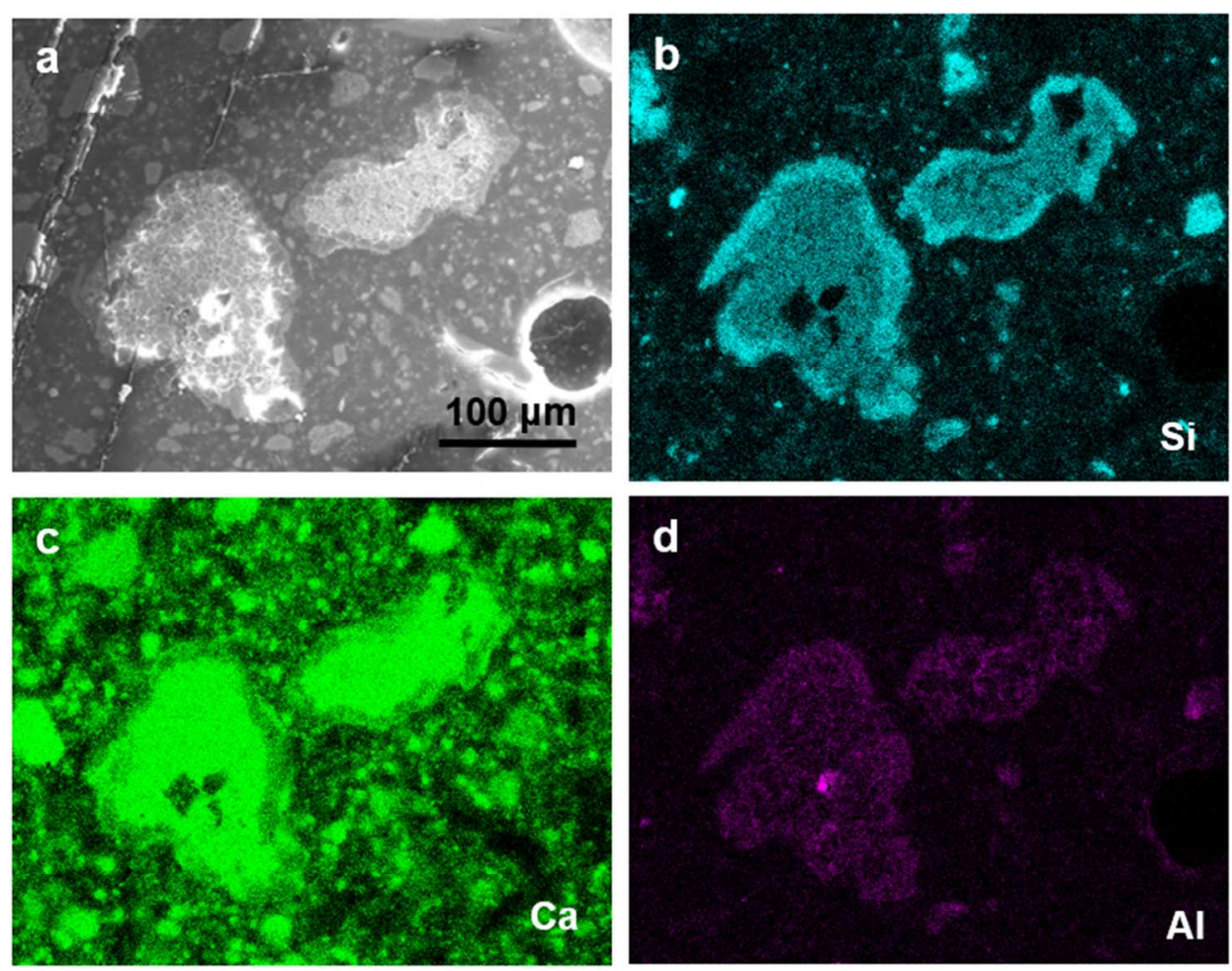

Scanning Electron Microscopy analysis of a CKD section after the carbonation experiment (T6). Backscattered electron image (a) and the results of $\mathrm{Si} \mathrm{(b),} \mathrm{Ca} \mathrm{(c),} \mathrm{and} \mathrm{Al} \mathrm{(d)} \mathrm{mapping} \mathrm{by} \mathrm{energy} \mathrm{dispersive}$ $\mathrm{X}$-ray on the CKD sample. Arrows indicate the Si-rich decalcified rim that envelops the residual noncarbonated grains of Ca-Al-silicates.

\section{$219 \times 173 \mathrm{~mm}(96 \times 96 \mathrm{DPI})$}


1

2

3

4

5

6

7

8

9

10

11

12

13

14

15

16

17

18

19

20

21

22

23

24

25

26

27

28

29

30

31

32

33

34

35

36

37

38

39

40

41

42

43

44

45

46

47

48

49

50

51

52

53

54

55

56

57

58

59

60

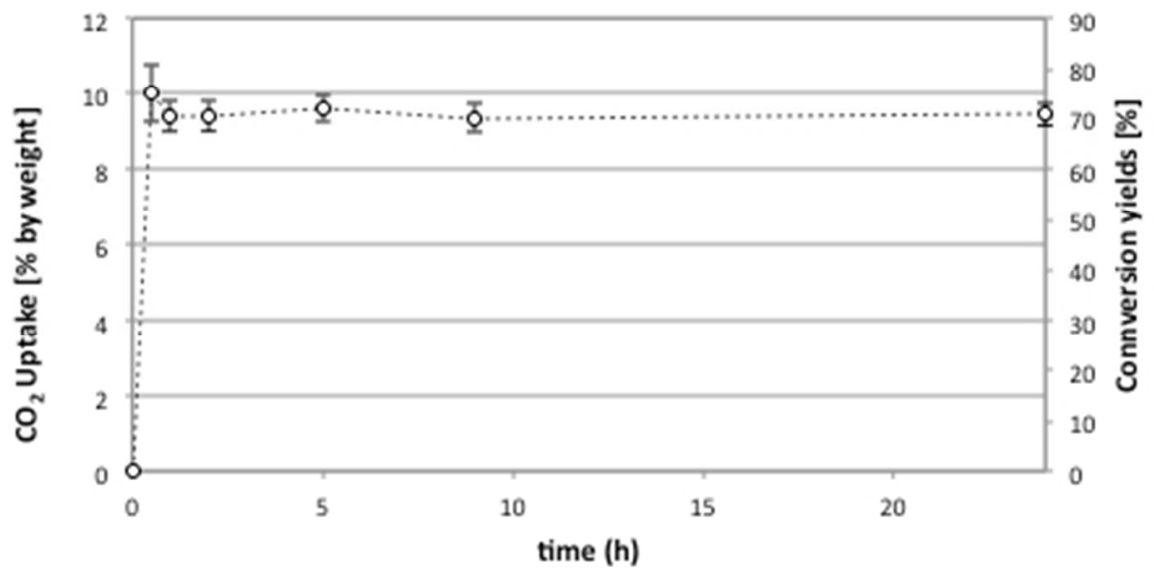

$\mathrm{CO}_{2}$ uptake and degree of sequestration in terms of reactive species conversion yields during the accelerated carbonation test.

$162 \times 83 \mathrm{~mm}(72 \times 72 \mathrm{DPI})$ 
Mean concentration of $\mathrm{Ca}, \mathrm{Mg}(\mathrm{a}), \mathrm{HCO}_{3}, \mathrm{SO}_{4}$ (b), $\mathrm{SiO}_{2}$ and $\mathrm{Al}$ (c) vs time in the liquid phase. Also, $\mathrm{Mg}^{2+} / \mathrm{Ca}^{2+}$ molar ratio is shown.

$132 \times 322 \mathrm{~mm}(120 \times 120 \mathrm{DPI})$ 

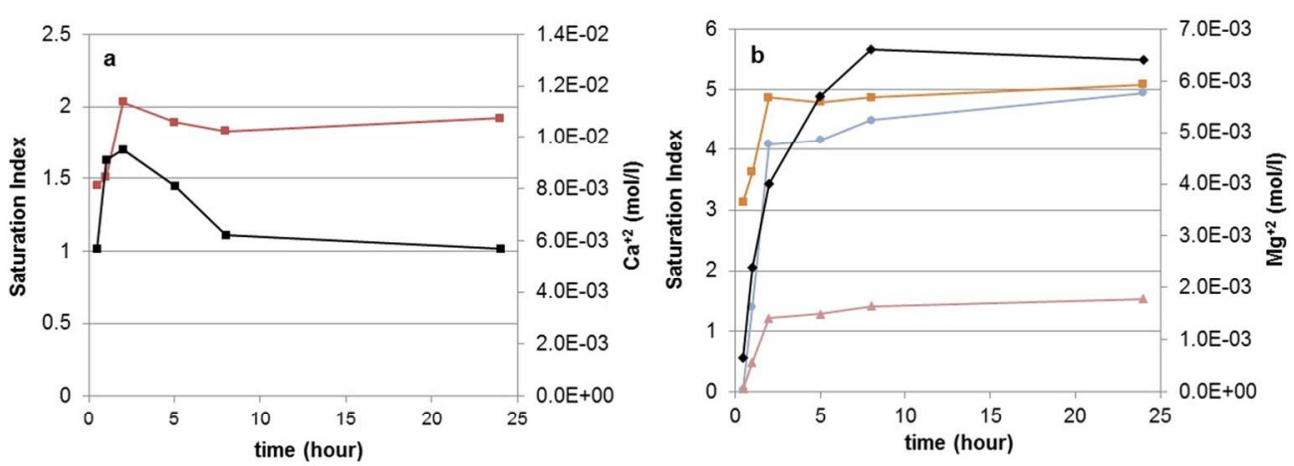

$\rightarrow-$ SI calcite $\rightarrow-\mathrm{Ca} 2+$

$\rightarrow$ SI dolomite $\rightarrow$ SI huntite $\rightarrow$ SI magnesite $\rightarrow-M g 2+$
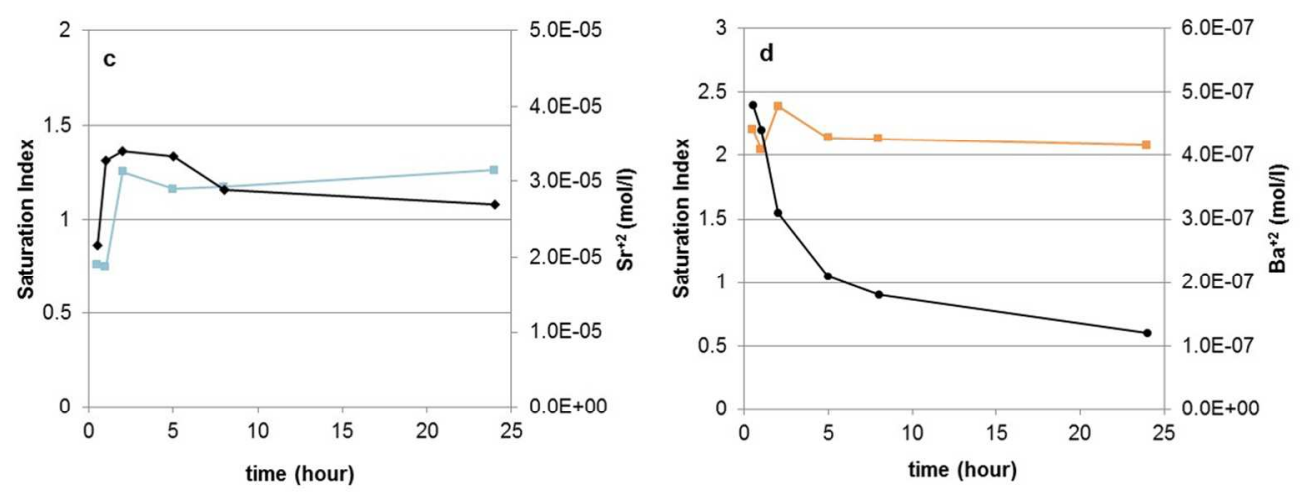

SI respect to calcite and $\mathrm{Ca}^{2+}$ activity vs time (a); SI respect to dolomite, huntite, magnesite and $\mathrm{Mg}^{2+}$ activity vs time (a); SI respect to strontianite and $\mathrm{Sr}^{2+}$ activity vs time (a); SI respect to witherite and $\mathrm{Ba}^{2+}$ activity vs time (a) in the liquid phase.

$329 \times 275 \mathrm{~mm}(96 \times 96 \mathrm{DPI})$ 


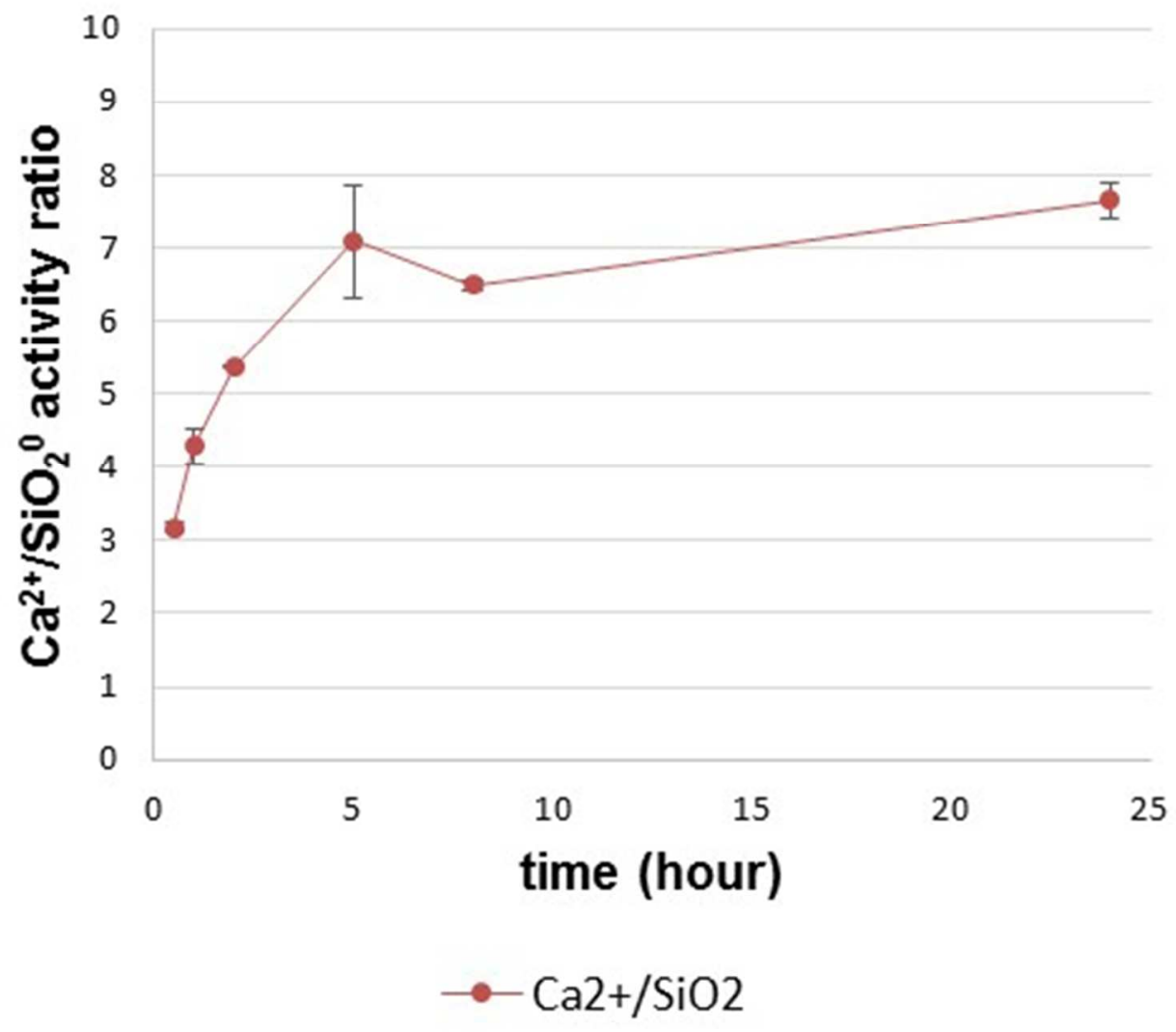

Mean $\mathrm{Ca}^{2+} / \mathrm{SiO}_{2}{ }^{0}$ activity ratio concentration vs time in the liquid phase. $105 \times 91 \mathrm{~mm}(120 \times 120$ DPI $)$

https://mc.manuscriptcentral.com/ghg-wiley 
pe vs pH diagrams for the system Ca-Al-C-Si-H-O for liquid phase collected at T1 (a) and T6 (b). Diagrams are drawn by the chemical equilibrium-diagram-tool Hydra/Medusa. Black circles indicate $\mathrm{pH}$ and pe values of the collected liquid phase at $\mathrm{T} 1$ (a) and T6 (b). Concentrations for $\mathrm{Ca}^{2+}-\mathrm{Al}^{3+}-\mathrm{CO}_{3}{ }^{2-}-\mathrm{H}_{4} \mathrm{SiO}_{4}{ }^{0} \mathrm{Come}$ from speciation calculation performed by PHREEQC.

$$
80 \times 184 \mathrm{~mm}(300 \times 300 \text { DPI })
$$

